\title{
SVA retrotransposon insertion-associated deletion represents a novel mutational mechanism underlying large genomic copy number changes with non-recurrent breakpoints
}

Julia Vogt ${ }^{1}$, Kathrin Bengesser ${ }^{1}$, Kathleen BM Claes ${ }^{2}$, Katharina Wimmer ${ }^{3}$, Victor-Felix Mautner $^{4}$, Rick van Minkelen ${ }^{5}$, Eric Legius ${ }^{6}$, Hilde Brems ${ }^{6}$, Meena Upadhyaya ${ }^{7}$, Josef Högel ${ }^{1}$, Conxi Lazaro ${ }^{8}$, Thorsten Rosenbaum ${ }^{9}$,

Simone Bammert ${ }^{1}$, Ludwine Messiaen ${ }^{10}$, David N Cooper ${ }^{7}$ and Hildegard Kehrer-Sawatzki ${ }^{*}$

\begin{abstract}
Background: Genomic disorders are caused by copy number changes that may exhibit recurrent breakpoints processed by nonallelic homologous recombination. However, region-specific disease-associated copy number changes have also been observed which exhibit non-recurrent breakpoints. The mechanisms underlying these non-recurrent copy number changes have not yet been fully elucidated.

Results: We analyze large NF1 deletions with non-recurrent breakpoints as a model to investigate the full spectrum of causative mechanisms, and observe that they are mediated by various DNA double strand break repair mechanisms, as well as aberrant replication. Further, two of the 17 NF1 deletions with non-recurrent breakpoints, identified in unrelated patients, occur in association with the concomitant insertion of SINE/variable number of tandem repeats/Alu (SVA) retrotransposons at the deletion breakpoints. The respective breakpoints are refractory to analysis by standard breakpoint-spanning PCRs and are only identified by means of optimized PCR protocols designed to amplify across GC-rich sequences. The SVA elements are integrated within SUZ12P intron 8 in both patients, and were mediated by target-primed reverse transcription of SVA mRNA intermediates derived from retrotranspositionally active source elements. Both SVA insertions occurred during early postzygotic development and are uniquely associated with large deletions of $1 \mathrm{Mb}$ and $867 \mathrm{~kb}$, respectively, at the insertion sites.
\end{abstract}

Conclusions: Since active SVA elements are abundant in the human genome and the retrotranspositional activity of many SVA source elements is high, SVA insertion-associated large genomic deletions encompassing many hundreds of kilobases could constitute a novel and as yet under-appreciated mechanism underlying large-scale copy number changes in the human genome.

\section{Background}

Large deletions encompassing the NF1 gene region at $17 q 11.2$ are present in 5 to $10 \%$ of patients with neurofibromatosis type 1 (NF1; MIM \#162200) [1]. The majority of large NF1 deletions have recurrent breakpoints and are mediated by nonallelic homologous recombination (NAHR) between various highly homologous duplicated sequences located within the NF1 gene region

\footnotetext{
* Correspondence: hildegard.kehrer-sawatzki@uni-ulm.de IInstitute of Human Genetics, University of Ulm, D-89081 Ulm, Germany Full list of author information is available at the end of the article
}

[2]. Three types of recurrent NAHR-mediated NF1 deletions have been identified, distinguishable by virtue of the locations of their breakpoints. Most frequent are type-1 NF1 deletions of $1.4 \mathrm{Mb}$, with breakpoints located within low-copy repeats termed NF1-REPa and NF1REPc [3-5]. It is estimated that 70 to $80 \%$ of all large NF1 deletions are type- 1 [6,7]. Less frequent are the type- 2 NF1 deletions, which span $1.2 \mathrm{Mb}$ and have their breakpoints located within the SUZ12 gene and its pseudogene SUZ12P. NAHR between SUZ12 and SUZ12P gives rise to type-2 NF1 deletions, which are observed in 10 to $20 \%$

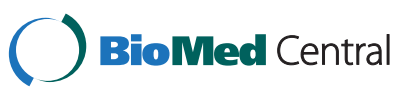

(C) 2014 Vogt et al.; licensee BioMed Central Ltd. This is an Open Access article distributed under the terms of the Creative Commons Attribution License (http://creativecommons.org/licenses/by/4.0), which permits unrestricted use, distribution, and reproduction in any medium, provided the original work is properly credited. The Creative Commons Public Domain Dedication waiver (http://creativecommons.org/publicdomain/zero/1.0/) applies to the data made available in this article, unless otherwise stated. 
of all large NF1 deletions [6,8]. By contrast, type-3 NF1 deletions, which are characterized by breakpoints located within NF1-REPb and NF1-REPc [7,9,10], are rare, accounting for only 1.4 to $4 \%$ of all large NF1 deletions [6,7]. All three types of NF1 deletion (that is, type-1, 2 and 3) are considered to exhibit recurrent breakpoints that occur preferentially within genomic regions encompassing only a few kilobases. In particular, type-1 NF1 deletions are characterized by pronounced breakpoint recurrence, with an estimated $80 \%$ of all type- 1 deletions exhibiting breakpoints located within an NAHR hotspot termed PRS2, which spans $2 \mathrm{~kb}[11,12]$. The existence of a recombination hotspot such as PRS2 is noteworthy since the recombining low-copy repeats, NF1-REPa and NF1-REPc, exhibit high sequence homology over an extended region encompassing approximately $50 \mathrm{~kb}$.

In addition to NF1 deletions with recurrent breakpoints mediated by NAHR between low-copy repeats, a number of NF1 deletions have been identified that appear to exhibit non-recurrent breakpoints. These so-called 'atypical NF1 deletions' tend to be heterogeneous in terms of their size and the number of genes located within the deleted region. An estimated 8 to $10 \%$ of all large NF1 deletions are atypical $[6,7]$. However, of the atypical NF1 deletions reported to date, only 6 have been characterized at the highest level of resolution so as to reveal the precise locations of the deletion breakpoints (Tables S1 and S2 in Additional file 1). None of these 6 deletions exhibited extended sequence homologies or additional rearrangements at their breakpoints, suggesting that non-homologous end joining (NHEJ) had been responsible for mediating them. Owing to the small number of atypical NF1 deletions so far characterized, it is unclear whether other mutational mechanisms are also involved. In this study, we identified and characterized the precise breakpoints of 17 atypical NF1 deletions and found that a variety of different mutational mechanisms, including replication-based mechanisms involving multiple template switching events and a novel SINE/variable number of tandem repeats/Alu (SVA) insertion-associated mechanism, are responsible for their occurrence.

\section{Results}

Custom-designed multiplex ligation-dependent probe amplification (MLPA) and targeted array comparative genomic hybridization (array $\mathrm{CGH}$ ) were performed to identify the breakpoint regions of the 17 atypical NF1 deletions spanning between $519 \mathrm{~kb}$ and $5.9 \mathrm{Mb}$ (Figure 1). Breakpointspanning PCRs, using the Expand Long Template PCR system under standard conditions with primers designed

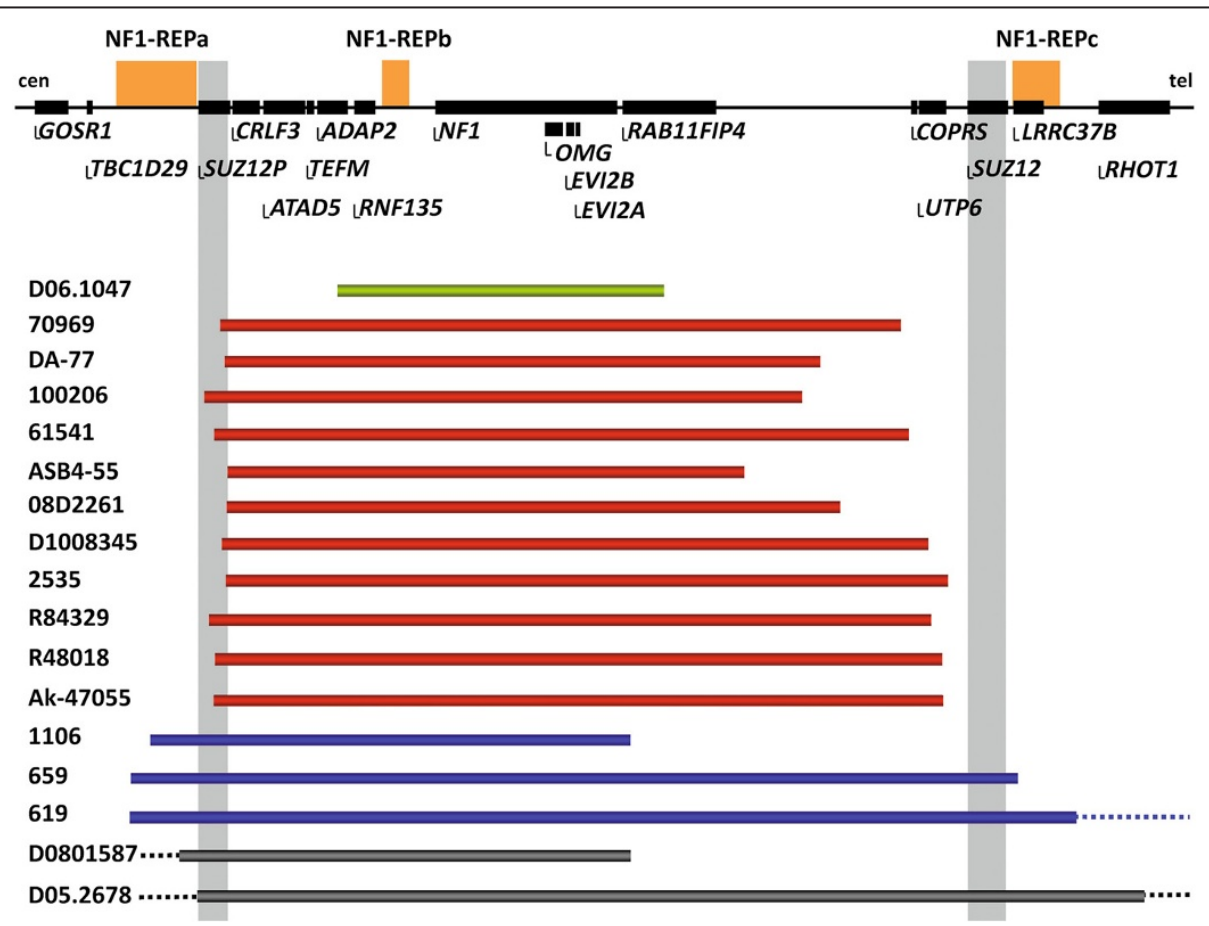

Figure 1 Location of the breakpoints of the 17 atypical NF1 deletions. At the top is a schematic representation of the NF1 gene and its flanking regions. The relative positions of the genes located within this region are denoted by horizontal black bars. Below, the extents of the 17 NF1 deletions analyzed are indicated by horizontal bars. The centromeric breakpoints of the deletions depicted by red bars are located within SUZ12P. None of these deletions had telomeric breakpoints located within SUZ12. The deletions depicted by blue bars exhibit breakpoints located within NF1-REPa. Two deletions (grey bars) extended beyond the region indicated here in a centromeric direction (indicated by dotted lines). The patient identification numbers are given on the left. cen, centromere; tel, telomere. 
on the basis of the array CGH results, were successful in the case of 15 of the 17 atypical NF1 deletions. Sequence analysis of the corresponding PCR products provided the precise breakpoint locations of the 15 deletions that exhibited simple breakpoints with readily interpretable transitions from centromeric to telomeric breakpoint-flanking sequences. Short microinsertions, of 9, 10 and $11 \mathrm{bp}$, respectively, were observed at the breakpoints of 3 of the 15 deletions (Table 1). These microinsertions were homologous to sequences located in the immediate vicinity of the breakpoint-flanking regions. Hence, the short microinsertions are likely to have been mediated by replicationassociated template switching, which will also have caused the large NF1 deletions identified in these patients (Figures S1 to S3 in Additional file 1). Microhomologies of between $1 \mathrm{bp}$ and $52 \mathrm{bp}$ were observed at the breakpoints of 13 of the 15 deletions, whereas 4 of these 13 deletions exhibited microhomologies $\geq 6$ bp (Table 1). Single nucleotide changes (SNCs) in relation to the human genome reference sequence that do not represent known polymorphisms (that is, not present in $\mathrm{dbSNP}$ ) were identified in the breakpoint-flanking regions of 4 of the 15 deletions (Table 1; Figure S4 in Additional file 1). The breakpoints of 3 of the 15 atypical NF1 deletions with simple breakpoints were located within Alu elements that exhibited pairwise sequence homologies between 79 and 89\% (Table 1), suggestive of Alu-mediated NAHR being the potential mechanism underlying the corresponding deletions.

\section{Analysis of deletion breakpoint-flanking regions}

We investigated whether non-B DNA-forming sequence motifs as well as direct and inverted repeats were overrepresented in the breakpoint-flanking regions of the 15 atypical NF1 deletions with simple breakpoints. To this end, we determined their frequency within a $300 \mathrm{bp}$ fragment flanking each deletion breakpoint (that is, $150 \mathrm{bp}$ on both sides). Non-B DNA-forming sequences were identified within $53 \%$ of the deletion breakpoint-flanking fragments (Tables S3 to S5 in Additional file 1). Similarly, direct and inverted repeats in the size range of $\geq 6 \mathrm{bp}$ up to $150 \mathrm{bp}$, as identified by MEME Suite sequence analysis tools, were detected in $77 \%$ of the deletion breakpointflanking regions (Table S6 in Additional file 1). However, when compared with a control sequence dataset, no overrepresentation of either non-B DNA-forming sequence motifs or direct and inverted repeats was detectable within the deletion breakpoint-flanking regions (Tables S5 and S6 in Additional file 1).

To determine the frequency of repeats $>150$ bp capable of forming DNA secondary structures and located within the breakpoint-flanking regions of 15 of the atypical NF1 deletions with simple breakpoints, we screened $2 \mathrm{~kb}$ sequences flanking the deletion breakpoints on either side by means of BLASTN self-alignments. Only 5 of the 15 deletion breakpoint-flanking regions harbored repeats in the size range of 244 to 316 bp (Table S7 in Additional file 1). As compared with a control dataset, the number of repeats was not found to be overrepresented in the deletion breakpoint-flanking regions $(P=0.99$, twotailed Fisher's exact test; Tables S8 and S9 in Additional file 1). We also searched for large direct and inverted repeats $(\geq 1 \mathrm{~kb})$ located within $20 \mathrm{~kb}$ regions flanking the deletion breakpoints on either side by means of BLASTN alignments. A $5.7 \mathrm{~kb}$ inverted repeat exhibiting 99\% sequence homology was identified that harbored one of the deletion breakpoints in patient 619. Remarkably, one of the breakpoints of another atypical NF1 deletion (in patient 659) was located only $2.7 \mathrm{~kb}$ telomeric to one of the breakpoints in patient 619 and between both $5.7 \mathrm{~kb}$ repeats (Figure S5 in Additional file 1). These inverted repeats were the only direct and inverted repeat sequences $\geq 1 \mathrm{~kb}$ identified in the vicinity of the breakpoints of the 15 atypical NF1 deletions (Table S10 in Additional file 1). We suspect that these $5.7 \mathrm{~kb}$ inverted repeats located within NF1-REPa may have contributed to the occurrence of the atypical NF1 deletions by mediating the formation of a hairpin structure, thereby inducing DNA double strand breaks underlying the deletions (Figure S5 in Additional file 1).

We also investigated whether SINEs and LINEs spanning the breakpoints, or located immediately adjacent to the breakpoints, might be overrepresented at the breakpoints of the 15 atypical NF1 deletions with simple breakpoints as compared with a control dataset of sequences. When the centromeric and telomeric breakpoints of the 15 atypical NF1 deletions with simple breakpoints were considered, SINEs or LINEs were located at or immediately adjacent to 22 of the 30 breakpoints (73\%). However, the number of SINEs and LINEs located at the NF1 deletion breakpoints was not significantly elevated as compared with a control sequence dataset (Table S11 in Additional file 1).

\section{SVA element insertions at the deletion breakpoints in two patients}

In contrast to the aforementioned 15 deletions with simple breakpoints, breakpoint-spanning PCRs were not successful under standard conditions in 2 of the 17 atypical NF1 deletions investigated. However, a combination of semi-specific PCR, inverse PCR and PCR analysis of somatic cell hybrids made it possible to narrow down the deletion breakpoint regions in patient DA-77 as schematically indicated in Figures S6 and S7 (Additional file 1). GenomeWalker analysis of the breakpoint regions in this patient then revealed the insertion of an SINE/ VNTR/Alu (SVA) retrotransposon, which is absent from the human genome reference sequence (hg19), at the 
Table 1 Breakpoint positions and sequence features of the 17 atypical NF1 deletions

\begin{tabular}{|c|c|c|c|c|c|c|c|c|c|}
\hline Patient & Breakpoint locations $^{a}$ & $\begin{array}{l}\text { Deletion size } \\
\text { (bp) }\end{array}$ & $\begin{array}{l}\text { Microhomology } \\
(\mathbf{b p})^{\mathbf{b}}\end{array}$ & $\begin{array}{l}\text { Insertion at } \\
\text { breakpoint }\end{array}$ & SNCs $^{c}$ & Mosaic & $\begin{array}{l}\text { Proximal (distal) } \\
\text { breakpoint location }\end{array}$ & $\begin{array}{l}\text { SINEs located at proximal } \\
\text { and distal breakpoints }{ }^{\mathrm{d}} \\
\text { [homology] }^{\mathrm{e}}\end{array}$ & $\begin{array}{l}\text { Postulated mutational } \\
\text { mechanism }^{f}\end{array}$ \\
\hline 08D2261 & $29,102,848(30,079,302)$ & 976,455 & - & - & - & Yes & $\begin{array}{l}\text { SUZ12P (between } \\
\text { RAB11FIP4 and COPRS) }\end{array}$ & - & NHEJ \\
\hline 100206 & $29,065,415(30,016,354)$ & 950,940 & - & - & + & Yes & $\begin{array}{l}\text { SUZ12P (between } \\
\text { RAB11FIP4 and COPRS) }\end{array}$ & - & $\mathrm{NHEJ/RBM}$ \\
\hline D1008345 & $29,094,424(30,218,204)$ & $1,123,781$ & 1 & - & - & No & SUZ12P (UTP6) & - & NHEJ \\
\hline D05.2678 & $28,142,439(34,112,082)$ & $5,969,644$ & 1 & - & - & No & SSH2 (MMP28) & - & NHEJ \\
\hline R84329 & $29,074,557(30,223,384)$ & $1,148,828$ & 1 & TGTCCCCTCTG & + & Yes & SUZ12P (UTP6) & - & NHEJ/RBM \\
\hline 70969 & $29,092,903(30,175,393)$ & $1,082,491$ & 1 & GGCCAGGTT & - & No & $\begin{array}{l}\text { SUZ12P (between } \\
\text { RAB11FIP4 and COPRS) }\end{array}$ & - & NHEJ/RBM \\
\hline 619 & $28,946,218(31,954,580)$ & $3,008,363$ & 2 & GTAGCAGAAT & - & No & NF1REPa (ASIC2) & - & NHEJ/RBM \\
\hline 61541 & $29,082,032(30,187,273)$ & $1,105,242$ & 2 & - & + & Yes & $\begin{array}{l}\text { SUZ12P (between } \\
\text { COPRS and UTP6) }\end{array}$ & - & NHEJ/RBM \\
\hline 2535 & $29,101,686(30,250,762)$ & $1,149,077$ & 2 & - & - & No & $\begin{array}{l}\text { SUZ12P (between } \\
\text { UTP6 and SUZ12) }\end{array}$ & - & NHEJ \\
\hline R48018 & $29,084,006(30,241,383)$ & $1,157,378$ & 2 & - & - & No & $\begin{array}{l}\text { SUZ12P (between } \\
\text { UTP6 and SUZ12) }\end{array}$ & - & NHEJ \\
\hline Ak-47055 & $29,082,023(30,243,011)$ & $1,160,989$ & 4 & - & - & Yes & $\begin{array}{l}\text { SUZ12P (between } \\
\text { UTP6 and SUZ12) }\end{array}$ & - & NHEJ \\
\hline D06.1047 & $29,264,225(29,783,515)$ & 519,291 & 6 & - & - & Yes & ADAP2 (RAB11FIP4) & - & MMEJ/RBM \\
\hline $659^{9}$ & $28,948,946(30,345,260)$ & $1,396,315$ & 20 & - & - & Yes & NF1REPa (NF1REPC) & $\begin{array}{c}\text { AluY (AluSp) } \\
\text { [84\% in } 135 \text { bp] }\end{array}$ & $\begin{array}{c}\text { Alu-mediated } \\
\text { NAHR/MMEJ/RBM }\end{array}$ \\
\hline 1106 & $29,001,813(29,765,892)$ & 764,080 & 24 & - & + & No & NF1REPa (RAB11FIP4) & $\begin{array}{l}\text { AluSz6 (FLAM_C) } \\
\text { [79\% in } 112 \text { bp] }\end{array}$ & $\begin{array}{c}\text { Alu-mediated } \\
\text { NAHR/MMEJ/RBM }\end{array}$ \\
\hline D0801587 & $27,726,501 \quad(29,729,864)$ & $2,003,364$ & 52 & - & - & Yes & TAOK1 (RAB11FIP4) & $\begin{array}{c}\text { AluY (A/uY) } \\
{[89 \% \text { in } 301 \mathrm{bp}]}\end{array}$ & $\begin{array}{c}\text { Alu-mediated } \\
\text { NAHR/MMEJ/RBM }\end{array}$ \\
\hline
\end{tabular}




\begin{tabular}{lccccccc}
\hline DA-77/grandmother & $29,100,005(30,101,550)$ & $1,001,546$ & 2 & SVA_F1 element & - & Yes $^{\text {h }}$ & $\begin{array}{c}\text { SUZ12P (between } \\
\text { RAB11FIP4 and COPRS) }\end{array}$ \\
ASB4-55 & $29,103,071(29,969,839)$ & 866,769 & - & SVA_F element & - & Yes & $\begin{array}{c}\text { SUZ12P (between insertion } \\
\text { RAB17FIP4 and COPRS) }\end{array}$ \\
\hline
\end{tabular}

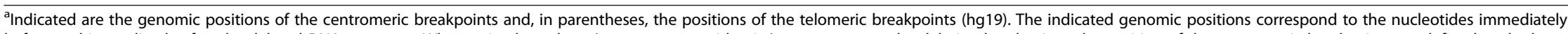
before and immediately after the deleted DNA sequence. Where microhomology (100\% sequence identity) was present at the deletion breakpoints, the position of the centromeric breakpoint was defined as the last nucleotide adjacent to the region of microhomology whilst the position of the telomeric breakpoint was defined as the first nucleotide adjacent to the region of microhomology.

${ }^{b}$ Indicated are the numbers of nucleotides exhibiting microhomology at the corresponding breakpoints. Microhomology was defined as one or more perfectly matching basepairs.

CPlus signs indicate single nucleotide changes (SNCS) identified within the breakpoint-flanking regions ( $\pm 75 \mathrm{bp}$ ) of the patients but absent from the reference sequence of the human genome (hg19). Where an SNC was identified within the breakpoint-flanking sequence, a replication-based mechanism (RBM) was considered to have been responsible for causing the SNC as well as the large NF1 deletion. Dashes indicate that SNCs were not detected in the respective breakpoint-flanking sequences.

${ }^{\mathrm{d}}$ SINEs and LINEs spanning the breakpoints were identified by means of the Repeat Masker track of the UCSC Genome Browser (date: 04.11.2013). Indicated are the Alu elements that were located at both breakpoints and in direct orientation with respect to each other. Dashes denote that directly oriented SINEs or LINEs located at both breakpoints and harboring the respective deletion breakpoints at homologous positions were not identified.

eIndicated is the homology between the Alu elements as well as the length of the Alu sequences exhibiting the indicated homology.

${ }^{f} \mathrm{NHEJ}$, non-homologous end joining; MMEJ, microhomology-mediated end joining; Alu-mediated NAHR,Alu-mediated nonallelic homologous end joining; RBM, replication-based mechanisms such as fork stalling and template-switching (FoSTeS) and microhomology-mediated break-induced replication (MMBIR). SVA insertion, SVA insertion-associated deletion.

The deletions in patients 100206 and 61541 may have been mediated by either NHEJ or RBM. In both patients, SNCs were detected in breakpoint-flanking regions suggestive of the involvement of a low-fidelity DNA polymerase and a RBM. However, the involement of NHEJ in the occurence of these deletions cannot be excluded in addition, the deletions identified in patients R84239, 70969 and 619 may have been caused by either NHEJ or RBM. The microinsertions identified at the breakpoints exhibit homology to sequences closely flanking the breakpoints and hence could have been caused by multiple template switching events indicative of a replication-based mechanism. However, we cannot exclude the possibility that the microinsertions occurred at random and that the deletions were mediated by NHEJ.

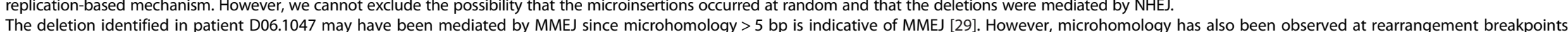
The deletion identified in patient D06.1047 may have been mediated by MMEJ since microhomology $>5$ bp is indicative of $M$ med by a replication-based mechanism and hence the deletion in this patient could also have been caused by an RBM.

In the case of patients 659, 1106 and D0801587, several mechanisms (Alu-mediated NAHR, MMEJ or RBM) could have caused the respective deletions. We observed directly oriented Alu elements at the deletion breakpoints of all three patients. Hence, the deletions may have been caused by Alu-mediated NAHR. Alternatively, the deletions could have been caused by MMEJ or RBM since microhomologies of 20 to 52 bp were observed at the breakpoints.

${ }^{9}$ The centromeric deletion breakpoint in patient 659 is located within intron 7 of the LRRC37Bpseudogene in NF1-REPa whereas the telomeric breakpoint is located within intron 2 of the functional LRRC37B gene located in NF1-REPc. The breakpoints of the deletion in patient 659 do not overlap with the nonallelic homologous recombination (NAHR) hotspots of type-1 NF1 deletions, termed PRS1 and PRS2. Hence, this atypical NF1 deletion is not considered to exhibit recurrent breakpoints located within regions of extended sequence homology.

${ }^{h}$ The grandmother of patient DA-77 exhibits somatic mosaicism since she possesses cells harboring the deletion alongside normal cells. Her granddaughter, patient DA-77, harbors the deletion in all of her cells. 
corresponding genomic position (Figure S6 in Additional file 1). SVA elements are composite retrotransposons that vary in size from $700 \mathrm{bp}$ up to $4 \mathrm{~kb}[13,14]$. In order to amplify across the inserted SVA element and the deletion breakpoints, we performed PCR using primers with a high melting-temperature and PCR conditions optimized to amplify GC-rich sequences (Figure S8 and Table S12 in Additional file 1). The application of an optimized PCR protocol was necessary since SVA elements contain a variable number of tandem repeats (VNTRs) region that is extremely GC-rich and can extend over several hundred basepairs. Sequence analysis of the resulting PCR product indicated that the inserted SVA spans $1.7 \mathrm{~kb}$ and exhibits 99\% sequence homology to its probable source element H10_1 located on chromosome 10q24.2 (Figure 2; Figure S9 in Additional file 1). H10_1 is known to be one of the most retrotranspositionally active SVA source elements so far identified in the human genome $[13,15]$. This source element belongs to the evolutionarily youngest subfamily of SVA elements (SVA_F1) and encompasses a VNTR region of 2,093 bp with a GC-content of 79\% (Figure 2; Figure S10 in Additional file 1). Compared with its source element H10_1, the SVA element inserted at the deletion breakpoint of patient DA-77 is truncated at its 5' end (Figure 2).

PCR-based techniques designed to identify unknown DNA sequence inserted at deletion breakpoints also facilitated the analysis of the atypical NF1 deletion identified in patient ASB4-55 (Figures S11 and S12 in Additional file 1). Inverse and semi-specific PCR indicated that the centromeric deletion breakpoint was located immediately adjacent to a poly $\mathrm{T}_{(40)}$ tract that is present in patient ASB4-55 but absent from the reference sequence of human chromosome 17 at the corresponding genomic position. Under the assumption that an SVA insertion could also have occurred in patient ASB4-55 at the breakpoint of the large NF1 deletion that was also refractory to analysis by breakpoint-spanning PCR under standard conditions, we performed breakpoint-spanning PCRs under conditions optimized to amplify across sequences with a high GC-content (Table S12 in Additional file 1 ). By these means, we successfully amplified across the deletion breakpoints, and sequence analysis of the PCR product confirmed the insertion of a SVA element in this patient as well (Figure S13 in Additional file 1). BLAT sequence alignments against the human genome reference sequence indicated that the inserted SVA exhibited maximum (99.5\%) sequence homology to the SVA_F element H6_1084 located on chromosome 6q22.31, which was therefore deemed most likely to be the source element of the SVA inserted at the deletion breakpoint in patient ASB4-55. Whereas full-length H6_1084 spans $2.69 \mathrm{~kb}$, the copy inserted at the deletion breakpoint in patient ASB4-55 spans only $1.3 \mathrm{~kb}$ and is $5^{\prime}$-truncated (Figure 2; Figures S14 and S15 in Additional file 1).
Remarkably, the sites of the two SVA insertions within SUZ12P intron 8, identified in patients ASB4-55 and DA-77, are separated by only 3,067 bp. SVA elements are thought to integrate within genomic sequences via targetprimed reverse transcription (TPRT) mediated by the LINE 1 protein machinery [16-19]. One of the hallmarks of L1-mediated retrotransposition of SVAs is that they often integrate at DNA sites resembling the L1 endonuclease consensus cleavage sites such as $5^{\prime}$-TTTT/A-3' or $5^{\prime}$-CTTT/A-3' [20]. The SVA elements we identified within SUZ12P intron 8 most likely integrated via TPRT since L1 endonuclease cleavage sites $5^{\prime}$-CTTT/A-3' were detected at the corresponding integration sites within SUZ12P intron 8 (Figures S16 and S17 in Additional file 1). Furthermore, long polyT tracts were noted at the integration sites; such tracts also represent hallmarks of L1-mediated TPRT (Figures S9 and S15 in Additional file 1). Both SVA elements identified at the deletion breakpoints of patients DA-77 and ASB4-55 were inserted into the plus strands within SUZ12P intron 8. The telomeric breakpoints of the deletions in patients DA-77 and ASB455 are separated by $132 \mathrm{~kb}$; whereas the deletion in patient DA-77 encompasses 1,001,546 bp, the deletion in patient ASB4-55 spans 866,769 bp.

Patient ASB4-55 exhibited somatic mosaicism, with 93\% of her blood cells harboring the deletion and 7\% lacking the deletion (Table S13 in Additional file 1). Somatic mosaicism was also detected in the grandmother of patient DA-77 who passed on the atypical NF1 deletion to her offspring (Figures S18 and S19 in Additional file 1). FISH analysis of blood cells from the grandmother of patient DA-77 indicated that $75 \%$ of her blood cells harbored the deletion whereas $25 \%$ were normal. The SVA insertion at the deletion breakpoints was confirmed by breakpoint-spanning PCR using DNA from the grandmother and the cousins of patient DA-77 (Figures S8 and S19 in Additional file 1).

Neither of the SVA elements identified at the NF1 deletion breakpoints appeared to be a frequent insertion/ deletion polymorphism within SUZ12P intron 8 as determined by PCR analysis of DNA samples derived from 100 healthy control individuals (Figures S20 and S22 and Table S14 in Additional file 1). Further, these SVA elements identified within SUZ12P intron 8 are not listed in the database of polymorphic retrotransposons, dbRIP [21], nor were they reported as SVA insertion polymorphisms in the 1000 Genomes Project dataset [22].

In order to confirm that the SVA insertions occurred de novo within SUZ12P intron 8 in patient ASB4-55 and the grandmother of patient DA-77, and to establish whether or not these insertions occurred prior to the somatic NF1 deletion, we performed PCR and SNP analysis using blood-derived DNA from the patients. These analyses did not indicate the presence of the SVA insertion in 
A

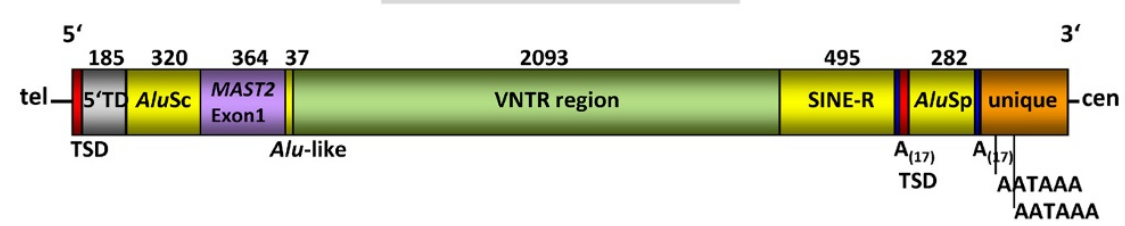

B

Patient DA-77

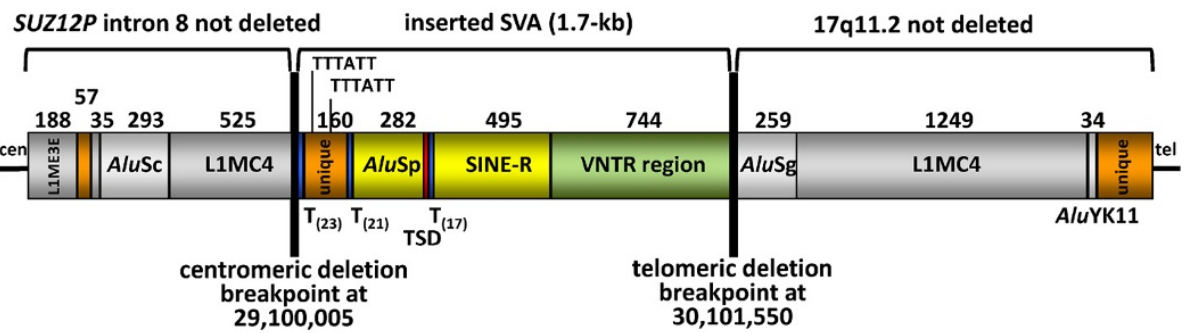

C

H6_1084 located at 6q22.31

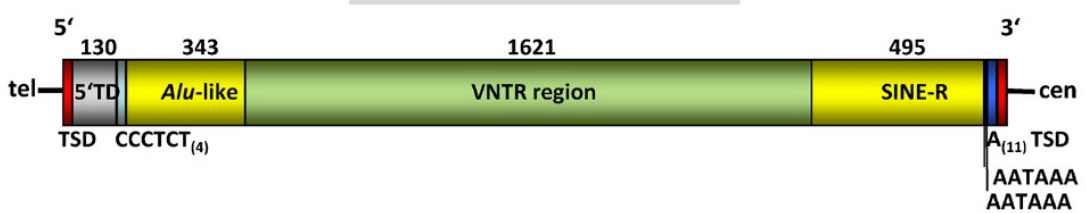

D Patient ASB4-55

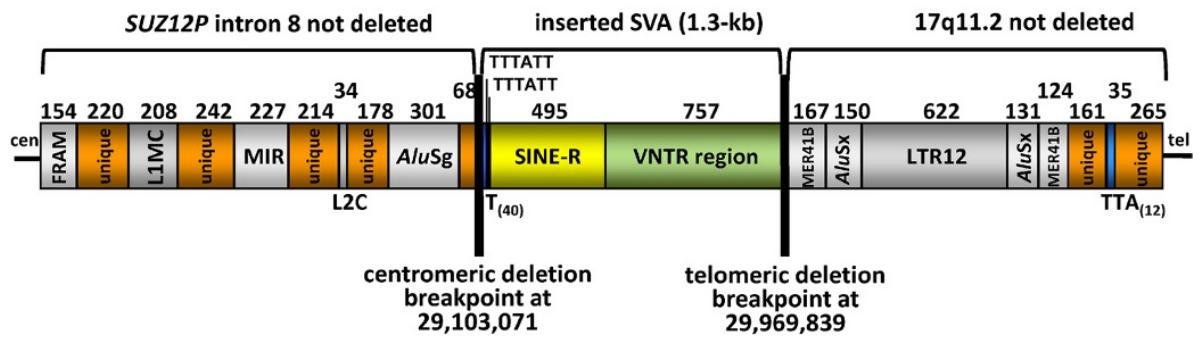

Figure 2 Structure of the SVA elements inserted at the NF1 deletion breakpoints and their source elements. (A) The SVA_F1 element H10_1 spans 4,039 bp and is the likely source element of the SVA copy that inserted within SUZ12P intron 8 in the grandmother of patient DA-77. Starting at its $5^{\prime}$ end, H10_1 comprises a target site duplication (TSD), a transduced sequence (5'TD) and a full-length AluSc from chromosome 9p13.3, a transduced partial exon 1 of MAST2, an Alu-like region, a variable number of tandem repeats (VNTR) region, a SINE-R, a polyA $A_{(17)}$ tract, the second TSD, an AluSp element, a second polyA $A_{(17)}$ tract and a non-repetitive, unique sequence resulting from a $3^{\prime}$ transduction that harbors two polyadenylation signals (AATAAA). The size of each region is given in basepairs. (B) A copy of the source element H10_1 integrated within SUZ12P intron 8 in the grandmother of patient DA-77. The SVA insertion was associated with a deletion of approximately $1 \mathrm{Mb}$. The inserted SVA spans $1.7 \mathrm{~kb}$ and is $5^{\prime}$ truncated. (C) Structure of the putative source SVA element H6_1084, which spans 2,691 bp and belongs to the SVA_F subfamily. A copy of H6_1084 is presumed to have integrated within SUZ12P intron 8 in patient ASB4-55. Full-length H6_1084 has the following structure starting from the 5' end: a TSD, a 5'TD from chromosome 12p11.21, a CCCTCT(4) repeat, a 343-bp Alu-like region, a GC-rich VNTR region, a SINE-R element, two polyadenylation signals, a polyA ${ }_{(11)}$ tract and the second TSD. The length of each region is indicated in basepairs. (D) Structure of the 5' truncated copy of H6_1084 that has integrated within SUZ12P intron 8 in patient ASB4-55. The SVA insertion was associated with an atypical NF1 deletion of $867 \mathrm{~kb}$. The SVA integration sites within SUZ12P intron 8 demarcate the centromeric breakpoints of the atypical NF1 deletions. 
the absence of the large NF1 deletion (Figures S20 to S23 and Table S15 in Additional file 1). Hence, we conclude that in both patients, the atypical NF1 deletions occurred concomitantly with the SVA insertions during early postzygotic development.

\section{Somatic mosaicism}

In addition to the mosaicism noted in patient ASB4-55 and in the grandmother of patient DA-77, a further eight of the 17 atypical NF1 deletions investigated were found to exhibit somatic mosaicism (Table S13 in Additional file 1). Thus, taken together, at least 10 of the 17 atypical NF1 deletions (59\%) were of postzygotic origin.

\section{Location of the atypical NF1 deletion breakpoints}

The 17 atypical NF1 deletions investigated here exhibited considerable differences in terms of their sizes and breakpoint locations (Figure 1). Nevertheless, the majority of the breakpoints were found to be located within the genomic region flanked by NF1-REPa and NF1-REPc. Only two deletions, those harbored by patients 619 and D05.2678, exhibited breakpoints telomeric to NF1-REPc (located 1.53 $\mathrm{Mb}$ and $3.69 \mathrm{Mb}$ distal to NF1-REPc). If these two deletions are excluded from consideration, the telomeric breakpoints of all of the remaining 15 atypical NF1 deletions were located within a $615-\mathrm{kb}$ region between RAB11FIP4 and NF1-REPc (Figure 3). Remarkably, 5 of these 15 deletions had telomeric breakpoints located within a $32.6 \mathrm{~kb}$ stretch, indicative of an overrepresentation of breakpoints within this genomic region (Table S16 in Additional file $1 ; P<0.0001)$. In addition, the centromeric breakpoints of the atypical NF1 deletions investigated were found to be preferentially located within a specific genomic region: 11 deletions exhibited centromeric breakpoints located within SUZ12P, thereby indicating an overrepresentation of such breakpoints within $39 \mathrm{~kb}$ of SUZ12P sequence (Figure 4; Table S17 in Additional file $1 ; P<0.0001)$. However, a clustering of these 11 deletion breakpoints within a specific region of SUZ12P encompassing only a few hundred basepairs was not observed (Table S18 in Additional file 1). This notwithstanding, the centromeric breakpoints of the unrelated patients Ak-45077 and 61541, located within SUZ12P intron 4, are separated by $10 \mathrm{bp}$ (Table 1; Table S18 in Additional file 1 ). It should be noted that the breakpoints of the recurrent type-2 NF1 deletions are also located within SUZ12P [23]. Although atypical NF1 deletions do not appear to be mediated by NAHR between segmental duplications, on the basis that extended sequence homology between the centromeric and telomeric deletion breakpoints was not evident, we noted that two of the atypical NF1 deletions investigated exhibited breakpoints that overlapped with the breakpoints of type-2 NF1 deletions (Table $\mathrm{S} 18$ in Additional file 1). The reasons why the centromeric breakpoints of the atypical NF1 deletions accumulate within SUZ12P are currently unknown. No overrepresentation of non-B DNA forming sequences, short repeats identified by MEME Suite analysis, or repeats $>150$ bp was observed in the regions flanking the breakpoints within SUZ12P as compared with a control sequence dataset (Tables S19 to 21 in Additional file 1).

\section{Discussion}

This study has provided a body of evidence to support the view that atypical NF1 deletions are not only heterogeneous in terms of their size but also heterogeneous in relation to their underlying mutational mechanisms. Sequence analysis of the deletion breakpoints suggested that replication- and recombination-based mechanisms as well as non-replicative repair and retrotransposon-associated mutagenesis are involved in the formation of these deletions. Fifteen of the 17 atypical NF1 deletions investigated exhibited 'simple' breakpoints that lacked microinsertions $>11$ bp at the breakpoint junctions (Table 1). Microhomologies ranging from 1 bp to 52 bp were detected at the breakpoints of 13 of these 15 atypical NF1 deletions with simple breakpoints. Other non-recurrent diseasecausing gross deletions have also been reported to exhibit breakpoint microhomologies at high frequency [24-26]. In our study, the majority of the atypical NF1 deletions $(10 / 17)$ exhibited short regions of microhomology (1 to $4 \mathrm{bp})$. We assume that some of these deletions with simple breakpoints and short regions of microhomology may have been mediated by NHEJ, a repair mechanism that is frequently associated with short microhomologies at deletion breakpoints although not dependent upon them (Table 1). By contrast, microhomology $>5$ bp is a prerequisite for microhomology-mediated end joining (MMEJ), an alternative pathway of NHEJ [27-30]. Four of the atypical NF1 deletions investigated here exhibited microhomologies $>5$ bp at the breakpoints and hence may have been mediated by MMEJ. Microhomologies have also been observed at the breakpoints of non-recurrent genomic rearrangements mediated by replication-based mechanisms such as microhomology-mediated breakinduced replication or fork stalling and template switching [26,31-37]. Hence, replication-based mechanisms may have been responsible for the atypical NF1 deletions exhibiting microhomologies at their breakpoints.

Three of the atypical NF1 deletions investigated here were characterized by microinsertions at the breakpoints of 9, 10 and $11 \mathrm{bp}$, respectively (Table 1). Sequence alignment indicated that these microinsertions exhibited homology to sequences closely flanking the deletion breakpoints (Figures S1 to S3 in Additional file 1). We conclude that these microinsertions probably resulted from serial template switching events during DNA replication that 


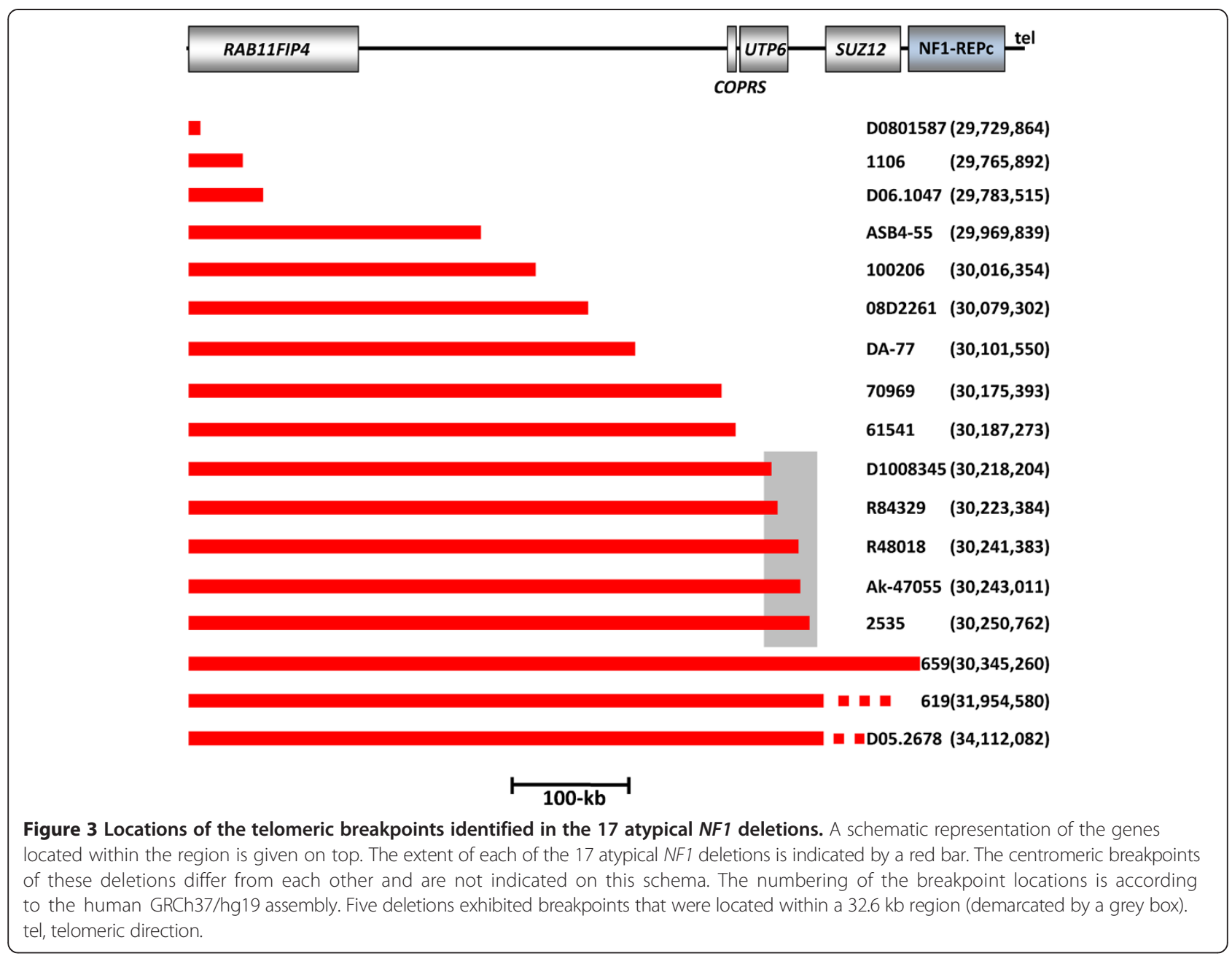

also caused the respective atypical large NF1 deletions. Also indicative of the involvement of replication-based mechanisms in the formation of some of the atypical NF1 deletions investigated are the SNCs that were observed in the breakpoint-flanking regions of 4 of the 15 atypical NF1 deletions with simple breakpoints (27\%; Table 1). These SNCs represent nucleotides that differ from the reference sequence of the human genome (hg19) but do not appear to represent polymorphisms since they are not present in dbSNP. Recently, Carvalho et al. [33] showed that replicative mechanisms underlying the complex copy number gains that characterize the $M E C P 2$ gene region are associated with an increased frequency of SNCs in the breakpoint-flanking regions. SNCs are likely to be caused by the involvement of low-fidelity DNA polymerases or a replisome with reduced fidelity [33]. In similar vein, we postulate that the SNCs observed in the breakpointflanking regions of the atypical NF1 deletions investigated here were introduced concomitantly with the occurrence of the large NF1 deletions mediated by replication-based mechanisms. At the breakpoints of three of the 15 atypical
NF1 deletions with simple breakpoints, directly orientated Alu elements were located and we surmise that these three deletions could have been caused by Alu-mediated nonallelic homologous recombination.

The different types of non-recurrent copy number change in the human genome are thought to be induced either by DNA double strand breaks or by secondary structures whose formation is facilitated by specific sequence motifs such as non-B DNA-forming sequences and direct and inverted repeats [38]. Indeed, non-B DNAforming sequences and/or inverted and direct repeats have been found to be overrepresented at the breakpoints of numerous human inherited disease-associated rearrangements [24,25,32,33,39-47]. This notwithstanding, we did not observe any overrepresentation of non-B DNA-forming sequences or direct/inverted repeats within 300 bp regions flanking the breakpoints of the 15 atypical NF1 deletions with simple breakpoints as compared with a control dataset of DNA sequences that did not encompass atypical NF1 deletion breakpoints (Tables S3 to S9 in Additional file 1). Nevertheless, we cannot exclude the 


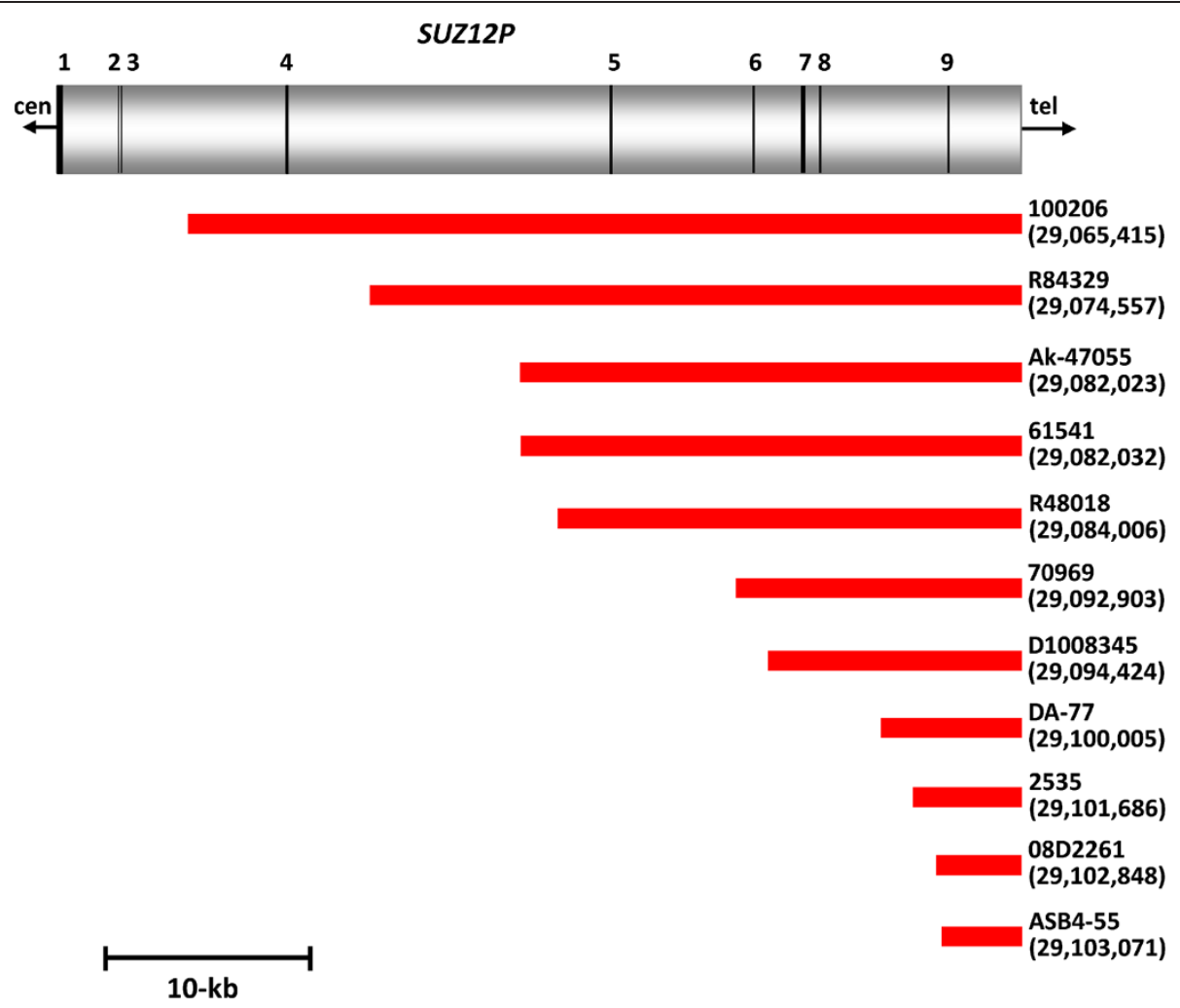

Figure 4 Centromeric breakpoint positions of the 11 atypical NF1 deletions with centromeric breakpoints located within SUZ12P. The exon-intron structure of SUZ12P is indicated as well as the numbering of the exons presented as vertical black lines. The extent of each of the 11 atypical NF1 deletions is shown by red bars. The telomeric breakpoints of these deletions differ from each other and are not indicated on this schema. The numbering of the centromeric breakpoint locations is given according to the human GRCh37/hg19 assembly. tel, telomeric direction.

possibility that the occurrence of some of the NF1 deletions investigated here may have been facilitated by DNA secondary structures formed by these repeat sequences. Remarkably, we identified a $5.7 \mathrm{~kb}$ inverted repeat at or flanking the breakpoints of two unrelated patients with atypical NF1 deletions (patients 659 and 619). It would appear likely that this $5.7 \mathrm{~kb}$ repeat, which exhibits $99 \%$ sequence identity, is causally associated with the occurrence of the corresponding deletions whose breakpoints are separated by only $2.7 \mathrm{~kb}$ (Figure S5 and Table S10 in Additional file 1).

The breakpoints of the atypical NF1 deletions investigated here turned out to be non-randomly distributed; indeed, we observed a preponderance of breakpoints within specific genomic regions (Figures 3 and 4). Most notably, 11 of the 17 deletions (65\%) possessed breakpoints that were located within SUZ12P. The pseudogene SUZ12P also harbors the breakpoints of the recurrent type-2 NF1 deletions mediated by NAHR. The high frequency of centromeric deletion breakpoints within SUZ12P suggests that this genomic region exhibits an unusual degree of genomic instability. At the outset of this study, we expected atypical NF1 deletions to be quite heterogeneous in terms of their size and breakpoint position. It turns out, however, that although this group of NF1 deletions has arisen through the action of a number of different mutational mechanisms, the deletion breakpoints exhibit a certain degree of clustering. This is consistent with the view that the nature, size and location of human gene mutations are often determined either by specific characteristics of the local DNA sequence environment or by higher order features of the genomic architecture [38,48].

Intriguingly, SVA element insertions within SUZ12P intron 8 were observed at the breakpoints of two unrelated patients with atypical NF1 deletions (patients DA-77 and ASB4-55). SVA elements are hominid-specific, nonautonomous, non-long terminal repeat retrotransposons that originated approximately 25 million years ago $[49,50]$. SVAs expand in their host genomes through an RNA intermediate and may integrate via Target-Primed Reverse Transcription (TPRT), which is mediated in trans by the L1 protein machinery $[16,19]$. Several active SVA source loci in the human genome are known to give rise to new insertions of SVA elements that may vary in size due to truncations or transductions at the $5^{\prime}$ or $3^{\prime}$ ends $[13,15,51]$. In the current reference sequence of the 
human genome (hg19), 2,676 SVA elements have been identified, encompassing $0.13 \%$ of the genome [52]. The SVA retrotransposition rate in humans has been estimated to be 1 in every 916 births [53,54]. SVAs are divided into subfamilies A to F1 based on diagnostic mutations, sequence divergence and evolutionary age $[13,15,55]$. One of the most active SVA elements is H10_1, located on chromosome 10q24.2, which has been identified as the source element of at least 13 further SVA_F1 elements in the human genome $[13,15]$. In our study, a 5 '-truncated copy of H10_1 was detected at the deletion breakpoints of patient DA-77. The SVA insertion and the associated atypical NF1 deletion had occurred de novo in the grandmother of patient DA-77 who exhibited somatic mosaicism with normal cells (Figures S18 and S19 in Additional file 1). The inserted SVA copy spans $1.7 \mathrm{~kb}$, and hence had been reduced in size compared with the 4 kb H10_1 source element (Figure 2). Remarkably, patient ASB4-55 also possessed a de novo insertion of a $5^{\prime}$ truncated SVA element at the breakpoints of the atypical NF1 deletion identified in this individual. The source element of this inserted SVA is likely to be H6_1084, which also belongs to the SVA_F subfamily but is located on chromosome 6q22.31 (Figure 2). The insertion of both SVA elements within SUZ12P intron 8 is likely to have been mediated by TPRT since long polyT tracts and sequences with homology to L1 endonuclease cleavage sites were both observed at the integration sites.

It is noteworthy that at least 10 of the 17 atypical NF1 deletions investigated (59\%) exhibited somatic mosaicism with normal cells. Hence, it is not only type- 2 NF1 deletions that are frequently of postzygotic origin $[23,56,57]$ but also atypical NF1 deletions. The atypical NF1 deletions detected in patient ASB4-55 and the grandmother of patient DA-77 must have occurred during postzygotic development since both individuals exhibited somatic mosaicism with normal cells. In neither individual did PCR experiments detect the presence of cells harboring the SVA insertion in the absence of the atypical NF1 deletion. Therefore, we may conclude that the SVA insertions are likely to have occurred concomitantly in association with the large NF1 deletions during postzygotic cell division. This is consistent with previous reports demonstrating that whilst retrotransposition can occur in the germline, it is also frequent in the soma in various tissues and developmental stages [58-60], in the brain [61-65] and during cancer progression [66-69]. According to the model presented in Figure 5, the SVA insertions within SUZ12P intron 8 were mediated by TPRT and were associated with ligation to sequences located in the telomeric $N F 1$ gene region, thereby giving rise to the large NF1 deletions. We postulate that a loop-like chromatin conformation may have brought SUZ12P and the region of the telomeric deletion breakpoint into close proximity. The physical interaction of these chromosomal regions may have then potentiated the ligation of the SUZ12P sequence, with the inserted SVA element at its end, to sequences located within the telomeric NF1 gene region. The ligations were probably potentiated by NHEJ since proteins of the NHEJ pathway have been shown to mediate L1 retrotransposition [70]. Importantly, we did not observe extended sequence homology between the inserted SVA elements and the telomeric deletion breakpoint regions in patients DA-77 and ASB4-55. This strongly suggests that the deletions arose concomitantly with the retrotransposition events as opposed to being mediated by secondary nonallelic homologous recombination events. We speculate that the insertion of the SVA elements triggered the occurrence of the large NF1 deletions according to the model proposed in Figure 5.

Previous studies have suggested the existence of retrotransposon insertion hotspots in the human genome [22,71-73]. This conceptual view is also supported by our observation of two de novo SVA insertions within SUZ12P intron 8 separated by only $3 \mathrm{~kb}$. Moreover, our findings suggest that the increased genomic instability manifested by SUZ12P not only causes recurrent type- 2 and atypical NF1 deletions, but may also facilitate the integration of SVA mRNA intermediates.

The SVA insertion-associated NF1 deletions identified in the family of patient DA-77 and in patient ASB4-55 encompassed $1 \mathrm{Mb}$ and $867 \mathrm{~kb}$, respectively. These deletions are unprecedentedly large since, until now, only much smaller deletions (up to $46 \mathrm{~kb}$ ) have been reported in association with pathogenic non-long terminal repeat (LTR) retrotransposon insertion-associated deletions in the human genome (Table 2). Thus, in a comparison of the human and chimpanzee genomes, Lee et al. [74] identified 13 human-specific SVA insertion-associated deletions ranging from $14 \mathrm{bp}$ up to $8.7 \mathrm{~kb}$ in length (Table S22 in Additional file 1). HeLa cell culture studies using an in vitro L1 recovery system have documented the occurrence of a genomic deletion $>71 \mathrm{~kb}$ associated with the insertion of an L1 element [75]. Thus, although large genomic deletions can in principle be mediated by a retrotransposon insertion-associated mechanism, this has until now not been reported in association with SVA insertion. Our findings imply that SVA insertion-associated large genomic deletions encompassing several hundred kilobases could represent a novel type of pathogenic (and conceivably also non-pathogenic) copy number change. At present, however, it is not possible to estimate the frequency of non-LTR retrotransposon insertion-associated large deletions causing human disease because this type of rearrangement is likely to have gone undetected in many studies.

Owing to their repetitive nature, SVA and other retrotransposon insertions at deletion breakpoints are undetectable by 


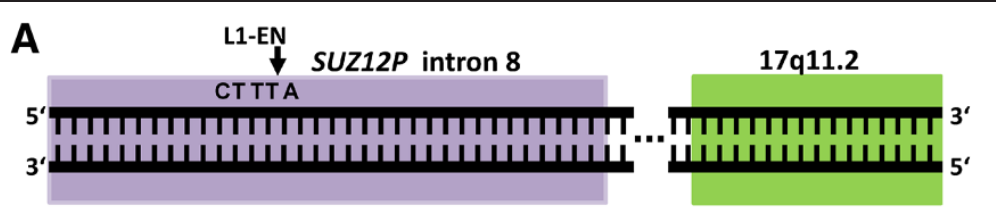

B
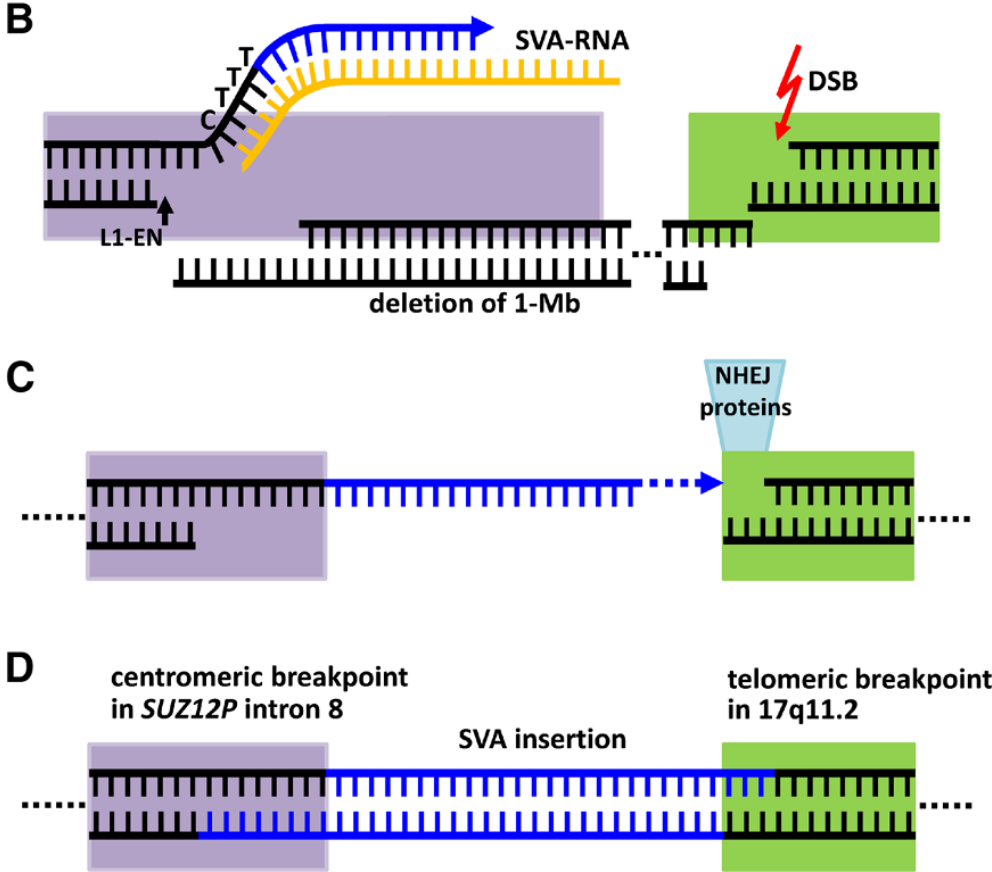

Figure 5 Putative mechanism underlying the large atypical NF1 deletions identified in patient ASB4-55 and the grandmother of patient DA-77. The deletions were associated with the insertion of an SVA element mediated by the LINE 1 protein machinery via target-primed reverse transcription. (A) SUZ12P intron 8 is indicated in lilac whereas the telomeric part of the NF1 region is shown in green. The dotted lines indicate the approximately 1-Mb distance between these two regions. The SVA insertion within SUZ12P intron 8 is likely to have been initiated by the L1 endonuclease (L1-EN), which will have introduced a nick at the consensus cleavage site $5^{\prime}-C T T T / A-3^{\prime}$. (B) Next, the SVA mRNA annealed to the T-overhang by means of its polyA-tail. Then, the L1 reverse transcriptase used the SVA mRNA as a template for reverse transcription to synthesize the SVA CDNA (blue). Second strand cleavage by the L1-EN occurred upstream of the first-strand cleavage site. Independently, a double strand break (DSB) occurred in the telomeric region of 17q11.2. (C,D) After dissociation of the SVA mRNA, the integration process was not finalized by recombinational repair using the downstream SUZ12P intron 8 sequence. Instead, the DNA ends were ligated by NHEJ to the open-ended DNA sequence located within the telomeric 17q11.2 region, between the RAB11FIP4 and COPRS genes, which resulted in the deletion of the intervening sequence and hence the occurrence of the atypical NF1 deletion (D).

array CGH. Furthermore, specially optimized PCR assays are necessary to detect the GC-rich SVA elements at deletion breakpoints because long GC-rich sequences are refractory to analysis by breakpoint-spanning PCRs performed under standard conditions. It follows that the incidence of SVA insertion-mediated deletions may well have been seriously underestimated in human genome pathology. Since the retrotransposition of non-LTR retro-elements occurs in the germline, early embryonic development, and in somatic cells [60-62], retrotransposon insertion-associated deletions are likely to occur in all three contexts.

\section{Conclusion}

It has been known for some time that retrotransposons can cause human disease by inactivating genes through insertional mutagenesis $[66,71,86,87]$. Our findings indicate that retrotransposon insertions may also exert their influence in a pathogenic context aggravated by accompanying large genomic deletions that encompass many hundreds of kilobases leading to the loss of multiple dosage-sensitive genes.

\section{Materials and methods \\ Patients}

The deletions analyzed in this study were identified by MLPA analysis (P122-C1 NF1-area kit, MRC-Holland, The Netherlands) in 17 unrelated NF1 patients who were referred for molecular diagnostics to the participating institutions (Tables S23 and S24 in Additional file 1). This study was approved by the Institutional Review Boards 
Table 2 Known de novo pathogenic retrotransposon insertions associated with deletions $\geq 100$ bp in the human genome

\begin{tabular}{|c|c|c|c|c|c|}
\hline Gene & Chromosomal location & Disease & Retrotransposon (length) & Length of the deletion & Reference \\
\hline$\overline{H L A-A}$ & $6 p 22.1$ & Leukemia $^{a}$ & SVA_F1 (2 kb) & $\sim 14 \mathrm{~kb}$ & {$[76]$} \\
\hline$A B C D 1$ & $\mathrm{Xq} 28$ & Adrenoleukodystrophy & AluYb9 (98 bp) & $4,726 \mathrm{bp}$ & [77] \\
\hline SERPINC1 & $1 \mathrm{q} 25.1$ & Antithrombin deficiency type 1 & Alu $(6 \mathrm{bp})^{\mathrm{b}}$ & $1,444 \mathrm{bp}$ & [78] \\
\hline$L P L$ & $8 p 21.3$ & Lipoprotein lipase deficiency & AluYb9 (150 bp) & $2.2 \mathrm{~kb}$ & [79] \\
\hline CHD7 & $8 q 12.2$ & CHARGE syndrome & AluYa5/8 (75 bp) & $10 \mathrm{~kb}$ & [80] \\
\hline PMM2 & $16 p 13.2$ & Congenital disorders of glycosylation type-la & AluYb8 (263 bp) & $28 \mathrm{~kb}$ & [81] \\
\hline$A P C$ & $5 q 22.2$ & Familial adenomatous polyposis & AluYb9 (93 bp) & $1,599 \mathrm{bp}$ & {$[82]$} \\
\hline EYA1 & $8 q 13.3$ & Branchio-oto-renal syndrome & L1 Hs (3,756 bp) & $17 \mathrm{~kb}$ & [83] \\
\hline PDHX & $11 p 13$ & Pyruvate dehydrogenase complex deficiency & L1 Hs (6,086 bp) & $46 \mathrm{~kb}$ & [84] \\
\hline$B R C A 1$ & $17 q 21.31$ & Hereditary breast/ovarian cancer & AluY ( 190 bp) & $23,363 \mathrm{bp}$ & {$[85]$} \\
\hline
\end{tabular}

${ }^{a}$ The germline SVA insertion-associated deletion was identified in three unrelated Japanese families. Of the individuals harboring the SVA insertion-associated deletion, one individual in each family presented with leukemia.

${ }^{\text {b}}$ The affected family members harbored an intragenic 1,444 bp deletion and an insertion of a polyT tract of 40 nucleotides followed by a 6 bp sequence (5'-GAGACG-3'). This 6 bp sequence, located at the 3'end of the insertion, was homologous to the consensus sequence of the free right Alu monomer (FRAM).

of Ulm University (application number 129/09) and the Hamburg Medical Association (PV3291) and we adhered to their rules. Either the patients or their parents gave their informed consent to the molecular characterization of the deletions. High-molecular-weight DNA samples extracted from blood of the patients were analyzed in order to identify the breakpoint locations.

\section{Custom-designed MLPA and array CGH}

To determine the positions of the deletion breakpoints more precisely, we performed custom-designed MLPA analysis with probes established previously (Table S25 in Additional file 1) [23]. By means of this analysis, the breakpoint regions could be assigned to intervals of a few tens of kilobases (Table S26 in Additional file 1). Next, we performed targeted array $\mathrm{CGH}$ using $8 \times 15 \mathrm{~K}$ arrays (Agilent Technologies, Santa Clara, CA, USA) with probes located within the deletion breakpoint regions as predicted by the MLPA analyses. This array CGH probe-set included 4,891 control probes as well as 10,853 test probes. The details of probe design, as well as the analysis of the array, are described in Figure S24 (Additional file 1).

\section{Breakpoint identification by PCR}

Breakpoint-spanning PCRs were performed using the Expand Long Template PCR system (Roche, Mannheim, Germany). The locations of the PCR primers were selected on the basis of the array CGH results (Table S27 in Additional file 1). The resulting PCR products were gel-purified (Zymoclean ${ }^{\mathrm{Tm}}$ Gel DNA Recovery Kit, Zymo Research, Irvine, CA, USA) and sequenced with the BigDye Terminator v3.1 Cycle Sequencing Kit (Life Technologies, Darmstadt, Germany). Sequence alignments of the breakpoint-spanning PCR products against the reference sequence of the human genome (hg19) indicated the precise locations of the respective deletion breakpoints.

\section{Somatic cell hybrids and PCR analysis}

Hybrid cell lines harboring only the chromosome 17 with the deletion were established for patients 659, 619, 1106, DA-77 and ASB4-55 using Epstein-Barr virus-transformed cell lines according to the procedure described previously [8]. Using DNA isolated from the hybrid cell lines, we performed PCR and sequence analysis of the respective products in order to narrow down the locations of the deletion breakpoints.

\section{Identification of large insertions at the deletion breakpoints in two patients}

Inverse PCR, semi-specific PCR, as well as GenomeWalker ${ }^{\mathrm{TM}}$ analysis were employed to investigate the insertions at the deletion breakpoints of patients DA-77 and ASB4-55. Inverse PCR, as schematically described in Figure S25 (Additional file 1), was performed with the restriction enzymes and PCR primers listed in Tables S28 and S29 (Additional file 1). Semi-specific PCRs, employed according to the principle described in Figure S26 (Additional file 1), were performed with primers summarized in Tables S30 and S31 (Additional file 1). PCR products obtained from these assays were then investigated by sequence analysis. To perform GenomeWalker ${ }^{\text {TM }}$ analysis (Clontech, Saint-Germain-en-Laye, France), genomic DNA ( $2.5 \mu \mathrm{g}$ per experiment) was restriction digested and adaptors were ligated to the DNA fragments. Subsequently, PCR was performed with an adaptor-specific primer in combination with a primer located close to the breakpoint regions (Figure S27 in Additional file 1). PCRs were performed with the Advantage 2 PCR Kit (Clontech). The 
corresponding PCR products were gel-purified (S.N.A.P. ${ }^{\mathrm{m}}$ UV-Free Gel Purification Kit, Invitrogen, USA) and cloned for sequence analyses. The restriction enzymes used for each experiment, together with the region-specific primers, are listed in Tables S32 and S33 (Additional file 1).

\section{Analysis of the breakpoint-flanking sequences}

Two datasets of sequences were analyzed in order to investigate whether non-B DNA-forming sequences, direct and inverted repeats $\geq 6 \mathrm{bp}$, or retrotransposons were overrepresented in the regions flanking the atypical NF1 deletion breakpoints. The dataset of deletion breakpointflanking sequences included $150 \mathrm{bp}$ located centromeric and $150 \mathrm{bp}$ located telomeric to each deletion breakpoint (Table S3 in Additional file 1). The control dataset included sequences that did not flank any known atypical NF1 deletion breakpoints; these control sequences were located within 17q11.2, telomeric to SUZ12P (genomic region: 29,118,000-29,148,000; hg19) and between RAB11FIP4 and COPRS (30,020,000-30,050,000; hg19). In total, the control dataset encompassed $60 \mathrm{~kb}$ of genomic DNA subdivided into 200 fragments of 300 bp each. Within each 300 bp fragment, a hypothetical breakpoint was assigned a location between nucleotides 150 and 151 (Table S4 in Additional file 1). This control dataset, as well as the breakpoint-flanking sequences of the NF1 deletions, were screened for the presence of non-B DNA sequence motifs (Tables S3 and S4 in Additional file 1). To this end, we used the non-B DNA database and the non-B DNA Motif Search Tool under preset search criteria for direct repeats (length: 10 to $150 \mathrm{bp}$, separated by < $10 \mathrm{bp}$ ) and inverted repeats (length: 6 to $150 \mathrm{bp}$, separated by $<100 \mathrm{bp)}$ [88]. In addition, we screened both datasets for the presence of direct and inverted repeats using the MEME suite software [89], which detects repeats irrespective of whether or not they are capable of forming non-B DNA structures. The repeats considered had a minimum length of $6 \mathrm{bp}$ with no restriction being placed upon the number of nucleotides between the repeats.

Both datasets were also investigated for the presence of retrotransposons by means of the UCSC Repeat Masker track [90] (Tables S3 and S4 in Additional file 1).

In order to search for direct and inverted repeats $>150 \mathrm{bp}$ exhibiting $\geq 87 \%$ sequence homology within $2 \mathrm{~kb}$ regions flanking the deletion breakpoint regions, we performed BLASTN [91] self-alignments of the respective regions. The number of such repeats was also determined in a control dataset of sequences derived from two genomic regions: one located telomeric to SUZ12P (genomic position: 29,118,000-29,210,000; $92 \mathrm{~kb}$ ), the other between RAB11FIP4 and COPRS (genomic position: 30,020,00030,048,000; $28 \mathrm{~kb})$. In total, these two regions comprised $120 \mathrm{~kb}$ of genomic DNA, which were subdivided into 30 fragments of $4 \mathrm{~kb}$ each. Hypothetical breakpoints were assigned locations between nucleotides at positions 2,000 and 2,001 of each of these $4 \mathrm{~kb}$ fragments. BLASTN alignments of $20 \mathrm{~kb}$ regions flanking the deletion breakpoints were performed to determine the occurrence of direct and inverted repeats $\geq 1 \mathrm{~kb}$ exhibiting $\geq 87 \%$ sequence homology.

\section{Somatic mosaicism}

Mosaicism of normal cells and cells harboring the NF1 deletion was sought in eight NF1 patients by FISH analysis of blood lymphocytes cultivated for $72 \mathrm{~h}$ in the presence of phytohaemagglutinin. In each case, at least 200 interphase nuclei were analyzed. When buccal cells were available for FISH analysis, approximately 100 interphase nuclei were evaluated. Mosaicism was also investigated by microsatellite marker analysis of DNA isolated from peripheral blood samples as described previously [8] and by PCR and sequence analysis of the insertion/deletion polymorphism rs17884042.

\section{Availability of data}

The microarray datasets are available from the Gene Expression Omnibus [92], accession number GSE57859.

\section{Additional file}

Additional file 1: Tables S1 to S33 and Figures S1 to S27.

\section{Abbreviations}

bp: base pair; CGH: comparative genomic hybridization; LINE: long interspersed nuclear element; LTR: long terminal repeat; MLPA: multiplex ligation-dependent probe amplification; MMEJ: microhomology-mediated end joining; NAHR: nonallelic homologous recombination;

NF1: neurofibromatosis type 1; NHEJ: non-homologous end joining;

PCR: polymerase chain reaction; SINE: short interspersed nuclear element; SNC: single nucleotide change; SVA: SINE/variable number of tandem repeats/Alu; TPRT: target-primed reverse transcription; VNTR: variable number of tandem repeats.

\section{Competing interests}

The authors declare that they have no competing interests.

\section{Authors' contributions}

$J V, K B, D N C$ and HKS conceived the study, performed data analysis and wrote the manuscript. JV, SB and KB performed the experiments. KBMC, KW, V-FM, RM, EL, HB, MU, CL, TR and LM identified the deletions and JH performed the statistical analysis. All authors read and approved the final manuscript.

\section{Acknowledgements}

This work was supported by grants from the Deutsche Forschungsgemeinschaft [KE 724/7-1 and KE 724/7-2] (HKS). JV is a PhD student of the Graduate School in Molecular Medicine at Ulm University. HB is a postdoctoral researcher of the Research Foundation Flanders (FWO) at the KU Leuven.

\section{Author details}

${ }^{1}$ Institute of Human Genetics, University of Ulm, D-89081 Ulm, Germany. ${ }^{2}$ Centre for Medical Genetics, Ghent University Hospital, B-9000 Ghent, Belgium. ${ }^{3}$ Division of Human Genetics, Medical University Innsbruck, A-6020 Innsbruck, Austria. ${ }^{4}$ Department of Neurology, University Hospital Hamburg Eppendorf, D-20246 Hamburg, Germany. ${ }^{5}$ Department of Clinical Genetics, 
Erasmus MC, NL-3015 Rotterdam, The Netherlands. ${ }^{6}$ Department of Human Genetics, KU Leuven, B-3000 Leuven, Belgium. 'Institute of Medical Genetics, School of Medicine, Cardiff University, Cardiff CF14 4XN, UK. ${ }^{8}$ Molecular Diagnostics Unit, Hereditary Cancer Program, Catalan Institute of Oncology (ICO-IDIBELL), L'Hospitalet de Llobregat, E-08908 Barcelona, Spain. ${ }^{9}$ Department of Pediatrics, Duisburg General Hospital, D-47055 Duisburg, Germany. ${ }^{10}$ Medical Genomics Laboratory, Department of Genetics, University of Alabama at Birmingham, Birmingham, Alabama 35294, USA.

Received: 5 February 2014 Accepted: 2 June 2014

Published: 2 June 2014

\section{References}

1. Kluwe L, Siebert R, Gesk S, Friedrich RE, Tinschert S, Kehrer-Sawatzki H, Mautner V-F: Screening of 500 unselected neurofibromatosis 1 patients for deletions of the NF1 gene. Hum Mutat 2004, 23:111-116.

2. Kehrer-Sawatzki H, Cooper DN: NF1 microdeletions and their underlying mutational mechanisms. In Neurofibromatosis Type 1, Molecular and Cellular Biology. Edited by Upadhyaya M, Cooper DN. Heidelberg: Springer; 2012:187-211

3. Dorschner MO, Sybert VP, Weaver M, Pletcher BA, Stephens K: NF1 microdeletion breakpoints are clustered at flanking repetitive sequences. Hum Mol Genet 2000, 9:35-46.

4. Jenne DE, Tinschert S, Reimann H, Lasinger W, Thiel G, Hameister H, Kehrer-Sawatzki H: Molecular characterization and gene content of breakpoint boundaries in patients with neurofibromatosis type 1 with 17q11.2 microdeletions. Am J Hum Genet 2001, 69:516-527.

5. López-Correa C, Dorschner M, Brems H, Lazaro C, Clementi M, Upadhyaya M, Dooijes D, Moog U, Kehrer-Sawatzki H, Rutkowski JL, Fryns JP, Marynen P, Stephens K, Legius E: Recombination hotspot in NF1 microdeletion patients. Hum Mol Genet 2001, 10:1387-1392.

6. Messiaen L, Vogt J, Bengesser K, Fu C, Mikhail F, Serra E, Garcia-Linares C, Cooper DN, Lazaro C, Kehrer-Sawatzki H: Mosaic type-1 NF1 microdeletions as a cause of both generalized and segmental neurofibromatosis type-1 (NF1). Hum Mutat 2011, 32:213-219.

7. Pasmant E, Sabbagh A, Spurlock G, Laurendeau I, Grillo E, Hamel MJ, Martin L, Barbarot S, Leheup B, Rodriguez D, Lacombe D, Dollfus H, Pasquier L, Isidor B, Ferkal S, Soulier J, Sanson M, Dieux-Coeslier A, Bièche I, Parfait B, Vidaud $M$, Wolkenstein $P$, Upadhyaya M, Vidaud $D$, members of the NF France Network: NF1 microdeletions in neurofibromatosis type 1, from genotype to phenotype. Hum Mutat 2010, 31:E1506-E1518.

8. Kehrer-Sawatzki H, Kluwe L, Sandig C, Kohn M, Wimmer K, Krammer U, Peyrl A, Jenne DE, Hansmann I, Mautner VF: High frequency of mosaicism among patients with neurofibromatosis type 1 (NF1) with microdeletions caused by somatic recombination of the JJAZ1 gene. Am J Hum Genet 2004, 75:410-423.

9. Bengesser K, Cooper DN, Steinmann K, Kluwe L, Chuzhanova NA, Wimmer K, Tatagiba M, Tinschert S, Mautner VF, Kehrer-Sawatzki H: A novel third type of recurrent NF1 microdeletion mediated by non-allelic homologous recombination between $\angle R R C 37 B$-containing low-copy repeats in 17q11.2. Hum Mutat 2010, 31:742-751.

10. Zickler AM, Hampp S, Messiaen L, Bengesser K, Mussotter T, Roehl AC, Wimmer K, Mautner VF, Kluwe L, Upadhyaya M, Pasmant E, Chuzhanova N, Kestler HA, Högel J, Legius E, Claes K, Cooper DN, Kehrer-Sawatzki H: Characterization of the nonallelic homologous recombination hotspot PRS3 associated with type-3 NF1 deletions. Hum Mutat 2012, 33:372-383.

11. Bengesser K, Vogt J, Mussotter T, Mautner VF, Messiaen L, Cooper DN, Kehrer-Sawatzki H: Analysis of crossover breakpoints yields new insights into the nature of the gene conversion events associated with large NF1 deletions mediated by nonallelic homologous recombination. Hum Mutat 2014, 35:215-226.

12. De Raedt T, Stephens M, Heyns I, Brems H, Thijs D, Messiaen L, Stephens K, Lazaro C, Wimmer K, Kehrer-Sawatzki H, Vidaud D, Kluwe L, Marynen P, Legius E: Conservation of hotspots for recombination in low-copy repeats associated with the NF1 microdeletion. Nat Genet 2006, 38:1419-1423.

13. Damert A, Raiz J, Horn AV, Lower J, Wang H, Xing J, Batzer MA, Lower R, Schumann GG: 5'-Transducing SVA retrotransposon groups spread efficiently throughout the human genome. Genome Res 2009, 19:1992-2008.

14. Konkel MK, Batzer MA: A mobile threat to genome stability, the impact of non-LTR retrotransposons upon the human genome. Semin Cancer Biol 2010, 20:211-221.
15. Hancks DC, Ewing AD, Chen JE, Tokunaga K, Kazazian HH Jr: Exon-trapping mediated by the human retrotransposon SVA. Genome Res 2009, 19:1983-1991

16. Hancks DC, Goodier JL, Mandal PK, Cheung LE, Kazazian HH Jr: Retrotransposition of marked SVA elements by human L1s in cultured cells. Hum Mol Genet 2011, 20:3386-3400.

17. Hancks DC, Mandal PK, Cheung LE, Kazazian HH Jr: The minimal active human SVA retrotransposon requires only the 5'-hexamer and Alu-like domains. Mol Cell Biol 2012, 32:4718-4726.

18. Ostertag EM, Goodier JL, Zhang Y, Kazazian HH Jr: SVA elements are nonautonomous retrotransposons that cause disease in humans. Am J Hum Genet 2003, 73:1444-1451.

19. Raiz J, Damert A, Chira S, Held U, Klawitter S, Hamdorf M, Löwer J, Strätling WH, Löwer R, Schumann GG: The non-autonomous retrotransposon SVA is trans-mobilized by the human LINE-1 protein machinery. Nucleic Acids Res 2012, 40:1666-1683.

20. Morrish TA, Gilbert N, Myers JS, Vincent BJ, Stamato TD, Taccioli GE, Batzer MA, Moran JV: DNA repair mediated by endonuclease-independent LINE-1 retrotransposition. Nat Genet 2002, 31:159-165.

21. Wang J, Song L, Grover D, Azrak S, Batzer MA, Liang P: dbRIP, a highly integrated database of retrotransposon insertion polymorphisms in humans. Hum Mutat 2006, 27:323-329.

22. Stewart C, Kural D, Stromberg MP, Walker JA, Konkel MK, Stutz AM, Urban AE, Grubert F, Lam HY, Lee WP, Busby M, Indap AR, Garrison E, Huff C, Xing J, Snyder MP, Jorde LB, Batzer MA, Korbel JO, Marth GT: A comprehensive map of mobile element insertion polymorphisms in humans. PLoS Genet 2011, 7:e1002236.

23. Vogt J, Mussotter T, Bengesser K, Claes K, Högel J, Chuzhanova N, Fu C, van den Ende J, Mautner VF, Cooper DN, Messiaen L, Kehrer-Sawatzki H: Identification of recurrent type-2 NF1 microdeletions reveals a mitotic nonallelic homologous recombination hotspot underlying a human genomic disorder. Hum Mutat 2012, 33:1599-1609.

24. Chen X, Shen Y, Zhang F, Chiang C, Pillalamarri V, Blumenthal I, Talkowski M, Wu BL, Gusella JF: Molecular analysis of a deletion hotspot in the NRXN1 region reveals the involvement of short inverted repeats in deletion CNVs. Am J Hum Genet 2013, 92:375-386.

25. Verdin H, D'haene B, Beysen D, Novikova Y, Menten B, Sante T, Lapunzina P, Nevado J, Carvalho CM, Lupski JR, De Baere E: Microhomology-mediated mechanisms underlie non-recurrent disease-causing microdeletions of the FOXL2 gene or its regulatory domain. PLoS Genet 2013, 9:e1003358.

26. Zhang F, Seeman P, Liu P, Weterman MA, Gonzaga-Jauregui C, Towne CF, Batish SD, De Vriendt E, De Jonghe P, Rautenstrauss B, Krause KH, Khajavi M, Posadka J, Vandenberghe A, Palau F, Van Maldergem L, Baas F, Timmerman $V$, Lupski JR: Mechanisms for nonrecurrent genomic rearrangements associated with CMT1A or HNPP, rare CNVs as a cause for missing heritability. Am J Hum Genet 2010, 86:892-903.

27. Lieber MR: The mechanism of human nonhomologous DNA end joining. J BiolChem 2008, 283:1-5.

28. Ma JL, Kim EM, Haber JE, Lee SE: Yeast Mre11 and Rad1 proteins define a Ku-independent mechanism to repair double-strand breaks lacking overlapping end sequences. Mol Cell Biol 2003, 23:8820-8828.

29. McVey M, Lee SE: MMEJ repair of double-strand breaks (director's cut), deleted sequences and alternative endings. Trends Genet 2008, 24:529-538.

30. Truong LN, Li Y, Shi LZ, Hwang PY, He J, Wang H, Razavian N, Berns MW, Wu X: Microhomology-mediated end joining and homologous recombination share the initial end resection step to repair DNA double-strand breaks in mammalian cells. Proc Natl Acad Sci USA 2013, 110:7720-7725,

31. Bauters M, Van Esch H, Friez MJ, Boespflug-Tanguy O, Zenker M, Vianna-Morgante AM, Rosenberg C, Ignatius J, Raynaud M, Hollanders K, Govaerts K, Vandenreijt K, Niel F, Blanc P, Stevenson RE, Fryns JP, Marynen P, Schwartz CE, Froyen G: Nonrecurrent MECP2 duplications mediated by genomic architecture-driven DNA breaks and break-induced replication repair. Genome Res 2008, 18:847-858.

32. Carvalho CM, Zhang F, Liu P, Patel A, Sahoo T, Bacino CA, Shaw C, Peacock S, Pursley A, Tavyev YJ, Ramocki MB, Nawara M, Obersztyn E, Vianna-Morgante AM, Stankiewicz P, Zoghbi HY, Cheung SW, Lupski JR: Complex rearrangements in patients with duplications of $M E C P 2$ can occur by fork stalling and template switching. Hum Mol Genet 2009, 18:2188-2203.

33. Carvalho CM, Pehlivan D, Ramocki MB, Fang P, Alleva B, Franco LM, Belmont $J W$, Hastings PJ, Lupski JR: Replicative mechanisms for CNV formation are error prone. Nat Genet 2013, 45:1319-1326. 
34. Hastings PJ, Ira G, Lupski JR: A microhomology-mediated break-induced replication model for the origin of human copy number variation. PLOS Genet 2009, 5:e1000327.

35. Hastings PJ, Lupski JR, Rosenberg SM, Ira G: Mechanisms of change in gene copy number. Nat Rev Genet 2009, 10:551-564.

36. Lee JA, Carvalho CMB, Lupski JR: A DNA replication mechanism for generating nonrecurrent rearrangements associated with genomic disorders. Cell 2007, 131:1235-1247.

37. Zhang F, Khajavi M, Connolly AM, Towne CF, Batish SD, Lupski JR: The DNA replication FoSTeS/MMBIR mechanism can generate genomic, genic and exonic complex rearrangements in humans. Nat Genet 2009, 41:849-853.

38. Cooper DN, Bacolla A, Férec C, Vasquez KM, Kehrer-Sawatzki H, Chen JM: On the sequence-directed nature of human gene mutation: the role of genomic architecture and the local DNA sequence environment in mediating gene mutations underlying human inherited disease. Hum Mutat 2011, 32:1075-1099.

39. Bacolla A, Jaworski A, Larson JE, Jakupciak JP, Chuzhanova N, Abeysinghe SS, O'Connell CD, Cooper DN, Wells RD: Breakpoints of gross deletions coincide with non-B DNA conformations. Proc Natl Acad Sci USA 2004, 101:14162-14167.

40. Carvalho CM, Ramocki MB, Pehlivan D, Franco LM, Gonzaga-Jauregui C, Fang P, McCall A, Pivnick EK, Hines-Dowell S, Seaver LH, Friehling L, Lee S, Smith R, Del Gaudio D, Withers M, Liu P, Cheung SW, Belmont JW, Zoghbi HY, Hastings PJ, Lupski JR: Inverted genomic segments and complex triplication rearrangements are mediated by inverted repeats in the human genome. Nat Genet 2011, 43:1074-1081.

41. Holkers M, de Vries AA, Gonçalves MA: Nonspaced inverted DNA repeats are preferential targets for homology-directed gene repair in mammalian cells. Nucleic Acids Res 2012, 40:1984-1999.

42. Kurahashi $H$, Inagaki $H$, Ohye $T$, Kogo H, Tsutsumi M, Kato T, Tong M, Emanuel BS: The constitutional $t(11 ; 22)$ : implications for a novel mechanism responsible for gross chromosomal rearrangements. Clin Genet 2010, 78:299-309.

43. Lobachev KS, Stenger JE, Kozyreva OG, Jurka J, Gordenin DA, Resnick MA Inverted Alu repeats unstable in yeast are excluded from the human genome. EMBO J 2000, 19:3822-3830

44. Sheridan MB, Kato T, Haldeman-Englert C, Jalali GR, Milunsky JM, Zou Y, Klaes R, Gimelli G, Gimelli S, Gemmill RM, Drabkin HA: A palindrome-mediated recurrent translocation with $3: 1$ meiotic nondisjunction, the $\mathrm{t}(8 ; 22)$ (q24.13;q11.21). Am J Hum Genet 2010, 87:209-218.

45. Voineagu I, Narayanan V, Lobachev KS, Mirkin SM: Replication stalling at unstable inverted repeats, interplay between DNA hairpins and fork stabilizing proteins. Proc Natl Acad Sci USA 2008, 105:9936-9941.

46. Wells RD: Non-B DNA conformations, mutagenesis and disease. Trends BiochemSci 2007, 32:271-278

47. Zhao J, Bacolla A, Wang G, Vasquez KM: Non-B DNA structure-induced genetic instability and evolution. Cell Mol Life Sci 2010, 67:43-62.

48. Dittwald P, Gambin T, Szafranski P, Li J, Amato S, Divon MY, Rodríguez Rojas LX, Elton LE, Scott DA, Schaaf CP, Torres-Martinez W: NAHR-mediated copy-number variants in a clinical population: mechanistic insights into both genomic disorders and Mendelizing traits. Genome Res 2013, 23:1395-1409.

49. Han K, Konkel MK, Xing J, Wang H, Lee J, Meyer TJ, Huang CT, Sandifer E, Hebert K, Barnes EW, Hubley R, Miller W, Smit AFA, Ullmer B, Batzer MA: Mobile DNA in Old World monkeys, a glimpse through the rhesus macaque genome. Science 2007, 316:238-240.

50. Wang H, Xing J, Grover D, Hedges DJ, Han K, Walker JA, Batzer MA: SVA elements, a hominid-specific retroposon family. J MolBiol 2005, 354:994-1007.

51. Xing J, Wang H, Belancio VP, Cordaux R, Deininger PL, Batzer MA: Emergence of primate genes by retrotransposon-mediated sequence transduction. Proc Natl Acad Sci USA 2006, 103:17608-17613.

52. Savage AL, Bubb VJ, Breen G, Quinn JP: Characterisation of the potential function of SVA retrotransposons to modulate gene expression patterns. BMC Evol Biol 2013, 13:101.

53. Cordaux R, Batzer MA: The impact of retrotransposons on human genome evolution. Nat Rev Genet 2009, 10:691-703.

54. Xing J, Zhang Y, Han K, Salem AH, Sen SK, Huff CD, Zhou Q, Kirkness EF, Levy S, Batzer MA, Jorde LB: Mobile elements create structural variation, analysis of a complete human genome. Genome Res 2009, 19:1516-1526.

55. Bantysh $O B$, Buzdin AA: Novel family of human transposable elements formed due to fusion of the first exon of gene MAST2 with retrotransposon SVA. Biochemistry (Mosc) 2009, 74:1393-1399.
56. Roehl AC, Mussotter T, Cooper DN, Kluwe L, Wimmer K, Högel J, Zetzmann M, Vogt J, Mautner VF, Kehrer-Sawatzki H: Tissue-specific differences in the proportion of mosaic large NF1 deletions are suggestive of a selective growth advantage of hematopoietic del(+/-) stem cells. Hum Mutat 2012, 33:541-550.

57. Steinmann K, Cooper DN, Kluwe L, Chuzhanova NA, Senger C, Serra E, Lazaro C, Gilaberte M, Wimmer K, Mautner V-F, Kehrer-Sawatzki H: Type-2 NF1 deletions are highly unusual by virtue of the absence of nonallelic homologous recombination hotspots and an apparent preference for female mitotic recombination. Am J Hum Genet 2007, 81:1201-1220.

58. Belancio VP, Roy-Engel AM, Pochampally RR, Deininger P: Somatic expression of LINE-1 elements in human tissues. Nucleic Acids Res 2010, 38:3909-3922.

59. Ergün S, Buschmann C, Heukeshoven J, Dammann K, Schnieders F, Lauke H, Chalajour F, Kilic N, Strätling WH, Schumann GG: Cell type-specific expression of LINE-1 open reading frames 1 and 2 in fetal and adult human tissues. J Biol Chem 2004, 279:27753-27763.

60. Kano H, Godoy I, Courtney C, Vetter MR, Gerton GL, Ostertag EM, Kazazian HH Jr: L1 retrotransposition occurs mainly in embryogenesis and creates somatic mosaicism. Genes Dev 2009, 23:1303-1312.

61. Baillie JK, Barnett MW, Upton KR, Gerhardt DJ, Richmond TA, De Sapio F, Brennan PM, Rizzu P, Smith S, Fell M, Talbot RT, Gustincich S, Freeman TC, Mattick JS, Hume DA, Heutink P, Carninci P, Jeddeloh JA, Faulkner GJ: Somatic retrotransposition alters the genetic landscape of the human brain. Nature 2011, 479:534-537.

62. Coufal NG, Garcia-Perez JL, Peng GE, Yeo GW, Mu Y, Lovci MT, Morell M, O'Shea KS, Moran JV, Gage FH: L1 retrotransposition in human neural progenitor cells. Nature 2009, 460:1127-1131.

63. Evrony GD, Cai $X$, Lee E, Hills LB, Elhosary PC, Lehmann HS, Parker JJ, Atabay KD, Gilmore EC, Poduri A, Park PJ, Walsh CA: Single-neuron sequencing analysis of $\mathrm{L} 1$ retrotransposition and somatic mutation in the human brain. Cell 2012, 151:483-496.

64. Muotri AR, Chu VT, Marchetto MC, Deng W, Moran JV, Gage FH: Somatic mosaicism in neuronal precursor cells mediated by $L 1$ retrotransposition. Nature 2005, 435:903-910.

65. Singer T, McConnell MJ, Marchetto MC, Coufal NG, Gage FH: LINE-1 retrotransposons, mediators of somatic variation in neuronal genomes? Trends Neurosci 2010, 33:345-354.

66. Iskow RC, McCabe MT, Mills RE, Torene S, Pittard WS, Neuwald AF, Van Meir EG, Vertino PM, Devine SE: Natural mutagenesis of human genomes by endogenous retrotransposons. Cell 2010, 141:1253-1261.

67. Lee E, Iskow R, Yang L, Gokcumen O, Haseley P, Luquette LJ 3rd, Lohr JG, Harris CC, Ding L, Wilson RK, Wheeler DA, Gibbs RA, Kucherlapati R, Lee C, Kharchenko PV, Park PJ, Cancer Genome Atlas Research Network: Landscape of somatic retrotransposition in human cancers. Science 2012, 337:967-971.

68. Shukla R, Upton KR, Muñoz-Lopez M, Gerhardt DJ, Fisher ME, Nguyen T, Brennan PM, Baillie JK, Collino A, Ghisletti S, Sinha S, lannelli F, Radaelli E, Dos Santos A, Rapoud D, Guettier C, Samuel D, Natoli G, Carninci P, Ciccarelli FD, Garcia-Perez JL, Faivre J, Faulkner GJ: Endogenous retrotransposition activates oncogenic pathways in hepatocellular carcinoma. Cell 2013, 153:101-111.

69. Solyom S, Ewing AD, Rahrmann EP, Doucet $T$, Nelson HH, Burns MB, Harris RS, Sigmon DF, Casella A, Erlanger B, Wheelan S, Upton KR, Shukla R, Faulkner GJ, Largaespada DA, Kazazian HH Jr: Extensive somatic L1 retrotransposition in colorectal tumors. Genome Res 2012, 22:2328-2338.

70. Suzuki J, Yamaguchi K, Kajikawa M, Ichiyanagi K, Adachi N, Koyama H, Takeda S, Okada N: Genetic evidence that the non-homologous end-joining repair pathway is involved in LINE retrotransposition. PLoS Genet 2009, 5:e1000461.

71. Chen JM, Stenson PD, Cooper DN, Férec C: A systematic analysis of LINE-1 endonuclease-dependent retrotranspositional events causing human genetic disease. Hum Genet 2005, 117:411-427.

72. Conley ME, Partain JD, Norland SM, Shurtleff SA, Kazazian HH Jr: Two independent retrotransposon insertions at the same site within the coding region of BTK. Hum Mutat 2005, 25:324-325.

73. Wimmer K, Callens T, Wernstedt A, Messiaen L: The NF1 gene contains hotspots for L1 endonuclease-dependent de novo insertion. PLoS Genet 2011, 7:e1002371.

74. Lee J, Ha J, Son SY, Han K: Human genomic deletions generated by SVA-associated events. CompFunct Genomics 2012, 2012:807270.

75. Gilbert N, Lutz-Prigge S, Moran JV: Genomic deletions created upon LINE-1 retrotransposition. Cell 2002, 110:315-325. 
76. Takasu M, Hayashi R, Maruya E, Ota M, Imura K, Kougo K, Kobayashi C, Saji $H$, Ishikawa Y, Asai T, Tokunaga K: Deletion of the entire HLA-A gene accompanied by an insertion of a retrotransposon. Tissue Antigens 2007, 70:144-150.

77. Kutsche K, Ressler B, Katzera HG, Orth U, Gillessen-Kaesbach G, Morlot S, Schwinger $E$, Gal $A$ : Characterization of breakpoint sequences of five rearrangements in L1CAM and ABCD1 (ALD) genes. Hum Mutat 2002, 19:526-535.

78. Beauchamp NJ, Makris M, Preston FE, Peake IR, Daly ME: Major structural defects in the antithrombin gene in four families with type I antithrombin deficiency-partial/complete deletions and rearrangement of the antithrombin gene. Thromb Haemost 2000, 83:715-721.

79. Okubo M, Horinishi A, Saito M, Ebara T, Endo Y, Kaku K, Murase T, Eto M: A novel complex deletion-insertion mutation mediated by Alu repetitive elements leads to lipoprotein lipase deficiency. Mol Genet Metab 2007, 92:229-233.

80. Udaka T, Okamoto N, Aramaki M, Torii C, Kosaki R, Hosokai N, Hayakawa T, Takahata N, Takahashi T, Kosaki K: An Alu retrotransposition-mediated deletion of CHD7 in a patient with CHARGE syndrome. Am J Med Genet A 2007, 143:721-726.

81. Schollen E, Keldermans L, Foulquier F, Briones P, Chabas A, Sánchez-Valverde F, Adamowicz M, Pronicka E, Wevers R, Matthijs G: Characterization of two unusual truncating PMM2 mutations in two CDG-la patients. Mol Genet Metab 2007, 90:408-413.

82. Su LK, Steinbach G, Sawyer JC, Hindi M, Ward PA, Lynch PM: Genomic rearrangements of the $A P C$ tumor-suppressor gene in familial adenomatous polyposis. Hum Genet 2000, 106:101-107.

83. Morisada N, Rendtorff N, Nozu K, Morishita T, Miyakawa T, Matsumoto T, Hisano S, lijima K, Tranebjaerg L, Shirahata A: Branchio-oto-renal syndrome caused by partial EYA1 deletion due to LINE-1 insertion. Pediatr Nephrol 2010, 25:1343-1348.

84. Miné M, Chen JM, Brivet M, Desguerre I, Marchant $\mathrm{D}$, de Lonlay P, Bernard A, Férec C, Abitbol M, Ricquier D, Marsac C: A large genomic deletion in the $P D H X$ gene caused by the retrotranspositional insertion of a full-length LINE-1 element. Hum Mutat 2007, 28:137-142.

85. Peixoto A, Pinheiro M, Massena L, Santos C, Pinto P, Rocha P, Pinto C, Teixeira MR: Genomic characterization of two large Alu-mediated rearrangements of the BRCA1 gene. J Hum Genet 2013, 58:78-83.

86. Hancks DC, Kazazian HH Jr: Active human retrotransposons, variation and disease. Curr Opin Genet Dev 2012, 22:191-203.

87. Kaer K, Speek M: Retroelements in human disease. Gene 2013, 518:231-241.

88. Cer RZ, Donohue DE, Mudunuri US, Temiz NA, Loss MA, Starner NJ, Halusa GN, Volforsky N, Yi M, Luke BT, Bacolla A, Collins JR, Stephens RM: Non-B DB v2.0, a database of predicted non-B DNA-forming motifs and its associated tools. Nucleic Acids Res 2013, 41:D94-D100.

89. MEME Suite. [http://meme.nbcr.net/meme/]

90. UCSC Repeat Masker. [http://genome.ucsc.edu/]

91. BLASTN. [http://blast.ncbi.nlm.nih.gov/Blast.cgi]

92. The NCBI Gene Expression Omnibus. [http://www.ncbi.nlm.nih.gov/geo/]

doi:10.1186/gb-2014-15-6-r80

Cite this article as: Vogt et al: SVA retrotransposon insertion-associated deletion represents a novel mutational mechanism underlying large genomic copy number changes with non-recurrent breakpoints. Genome Biology 2014 15:R80.

\section{Submit your next manuscript to BioMed Central and take full advantage of:}

- Convenient online submission

- Thorough peer review

- No space constraints or color figure charges

- Immediate publication on acceptance

- Inclusion in PubMed, CAS, Scopus and Google Scholar

- Research which is freely available for redistribution

Submit your manuscript at www.biomedcentral.com/submit 